\title{
Kinetic Study on the Hydrolysis of p-nitrophenyl picolinate Catalyzed by g-C3N4/LaNiO3-Perovskite- type Oxides
}

\section{Changyu Ye}

Beijing normal university

\section{Rui Wang}

Beijing normal university

\section{Haoyu Wang}

Beijing normal university

\section{Huixing Zhang}

Beijing normal university

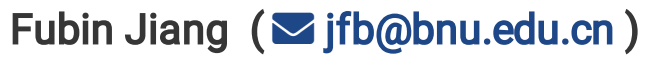

Beijing normal university https://orcid.org/0000-0003-2120-2827

\section{Research article}

Keywords: Perovskite-type oxides, Catalytic hydrolysis reaction, p-nitrophenyl picolinate, kinetics model

Posted Date: August 6th, 2020

DOl: https://doi.org/10.21203/rs.3.rs-53784/v1

License: (c) (1) This work is licensed under a Creative Commons Attribution 4.0 International License. Read Full License 
Kinetic Study on the Hydrolysis of p-nitrophenyl picolinate Catalyzed by $\mathrm{g}_{-} \mathrm{C}_{3} \mathrm{~N}_{4} / \mathrm{LaNiO}_{3}$-Perovskite-type Oxides

Changyu Ye, Rui Wang, Haoyu Wang, Huixing Zhang,Fubin Jiang*

Department of Chemistry, Beijing Normal University, Beijing, 100875, China

*Corresponding author email: jfb@bnu.edu.cn（Prof. Fubin Jiang）

Tel.: +8601058802850 


\section{Abstract}

$\mathrm{LaNiO}_{3}$-Perovskite-type oxides, as a novel hydrolytic catalyst, were synthesized using a sol-gel-calcination method, and were characterized by employing x-ray Diffraction (XRD), Scanning Electron Microscopy (SEM), and Brunauer-Emmett-Teller (BET). It was revealed that $\mathrm{LaNiO}_{3}$ and $2 \% \mathrm{~g}-\mathrm{C}_{3} \mathrm{~N}_{4} / \mathrm{LaNiO}_{3}$ -Perovskite-type oxides are nanoparticles about $12 \mathrm{~nm}$ and $10 \mathrm{~nm}$ easily agglomerated in large amounts, and the specific surface area of $\mathrm{LaNiO}_{3}$ is $21.277 \mathrm{~m}^{2} / \mathrm{g}$ and $2 \%$ g- $\mathrm{C}_{3} \mathrm{~N}_{4} / \mathrm{LaNiO}_{3}$ is $26.645 \mathrm{~m}^{2} / \mathrm{g}$, respectively. The results also indicate that there are irregular microporoes in the material. In the catalytic activity test, the absorption spectra were collected when hydrolysis of p-nitrophenyl picolinate (PNPP) $\left(\mathrm{C}_{\mathrm{PNPP}}=1-5 \times 10^{-5} \mathrm{~mol} / \mathrm{L}\right)$ was catalyzed by $\mathrm{LaNiO}_{3}(0.5 \mathrm{~g} / \mathrm{L})$ and $2 \% \mathrm{~g}-\mathrm{C}_{3} \mathrm{~N}_{4} / \mathrm{LaNiO}_{3}$ $(0.5 \mathrm{~g} / \mathrm{L})$ in buffer solution at different $\mathrm{pH}$ values (6.5-7.8), respectively. Based on the absorption spectrum data, the pseudo first-order rate constant is estimated to be $0.59 \mathrm{~min}^{-1}$ and $1.14 \mathrm{~min}^{-1}$, respectively. In addition, the proposed kinetics model of this reaction was confirmed by the results of the spectrum and the calculations.

Keywords: Perovskite-type oxides, Catalytic hydrolysis reaction, p-nitrophenyl picolinate, kinetics model 


\section{Introduction}

Enzymes are known for their efficient catalysis of reactions in the body. However, the limitations of natural enzymes such as limited source, instability, complex structure and short life span have restricted their applications in research. People are concerned about the mechanism of carboxylesterase catalysis in vivo and how to achieve catalysis in vitro, How to simulate the synthesis of simple artificial enzymes and construct a chemical model for natural enzyme simulation has aroused widespread interests.[1, 2]

In recent decades, the decomposition of carboxylic acid esters by metallomicelles based on the polymetallic active sites of natural enzymes has rapidly developed. The PNPP (p-nitrophenyl picolinate) is often used as a model of carboxylesterase to study the kinetic process of catalytic hydrolysis. Bin Xu et al.[3] reported that the catalytic constant $k_{\text {cat }}\left(1111 \mathrm{~s}^{-1}\right)$ for the $\mathrm{Cu}_{2} \mathrm{~L}(\mathrm{OAc})$-induced PNPP hydrolysis is about 1.8 times greater than that for the CuHL-promoted hydrolysis of $\operatorname{PNPP}\left(625 \mathrm{~s}^{-1}\right)$. At the same time, the binding between PNPP and the binuclear $\mathrm{Cu}_{2} \mathrm{~L}(\mathrm{OAc})$ is much easier than that of PNPP to CuHL. In the above two metal mimetic models, copper ions were used to mimic the active center structure of the enzyme. Although metal micelles have high catalytic activity, their application is limited because they cannot be reused. Dr. Xiao-lan Huang provided us with a new idea -- inorganic enzyme[4]. Huang previously reported that inorganic iron ion solutions, in which iron oxide nanoparticles are adsorbed in dialysis membrane tubes, significantly promote the hydrolysis of various phosphate esters, including inorganic 
polyphosphates, with the same kinetics as enzymes. The results of the study on iron oxide, vanadium pentoxide and molybdenum trioxide nanoparticles showed that they simulated peroxidase, bromine peroxidase and sulfite oxidase, respectively. All the above results indicated that the oxygen-metal bond in the oxide nanoparticles could simulate the functions of these corresponding natural metalloproteins. Inorganic biocatalysts no longer follow the traditional approach of replicating enzymes, supporting the hypothesis of metabolic precedence. As biocatalysts, these inorganic nanoparticles with enzyme-like activity may have acted in the natural terrestrial environment, and may have also acted in the early earth environment. They may have played an important role in the metabolic pathways of $\mathrm{C}, \mathrm{H}, \mathrm{O}, \mathrm{S}$ and $\mathrm{P}$ in the emergence and early evolution of life. Can we find an inorganic enzyme like this? Perovskite has become an important new material in the mixed oxide family because of its excellent thermal stability, mechanical stability, electronic structure, ionic conductivity, electron mobility and redox ability, as well as its low cost[5]. It has good performance in eliminating toxic compounds under photocatalysis.

As known for their multimetal ions, perovskite material is a kind of composite metal oxide with natural mineral $\mathrm{CaTiO}_{3}$ structure, which is represented by the general formula $\mathrm{ABO}_{3}$. In this structure, A-site ions on the corners of the lattice, and B-site ions on the center of the lattice, and oxygen ions form 12 coordination or 6 coordination. Usually, A is mostly rare earth, alkaline earth or alkali metal ion, and B is a transition metal of $3 \mathrm{~d}, 4 \mathrm{~d}$ or $5 \mathrm{~d}$ configuration[6]. In recent years, perovskites have been widely used for solar cells[7, 8], photocatalysis[9, 10] and other fields[11-13]. 
The B-site metal cation in the perovskite structure has a significant effect on the catalytic activity. However, its application to catalyze the hydrolysis of esters has not been reported. Jin Luo et al. [14]designed and constructed a z-type hybrid composed of $\mathrm{LaNiO}_{3}$ nanoparticles and $\mathrm{g}-\mathrm{C}_{3} \mathrm{~N}_{4}$ nanometers by a simple heat treatment method. As expected, compounds significantly improved tetracycline (TC) degradation in aqueous solutions under visible light irradiation $(>420 \mathrm{~nm})$. The TC degradation rate was up to $0.00282 \mathrm{~min}^{-1}, 3.8$ and 3.9 times higher than pure $\mathrm{g}-\mathrm{C}_{3} \mathrm{~N}_{4}$ and pure $\mathrm{LaNiO}_{3}$. Due to the synergistic effect between $\mathrm{LaNiO}_{3}$ and $\mathrm{g}-\mathrm{C}_{3} \mathrm{~N}_{4}$, the enhancement of photocatalytic activity is mainly attributed to the formation of $\mathrm{z}-\mathrm{LaNiO}_{3} / \mathrm{g}-\mathrm{C}_{3} \mathrm{~N}_{4}$ heterojunction, which not only promotes the interfacial charge transfer efficiency, but also preserves the redox ability of strong light generating electrons and holes. I. Rossetti et al. [15] synthesized $\mathrm{La}_{1-\mathrm{x}} \mathrm{Ag}_{\mathrm{x}} \mathrm{MnO}_{3 \pm \delta}, \mathrm{x}=0 ; 0.05 ; 0.10$; The activity of the catalysts prepared by FP is always higher than that of the catalysts prepared by SG with the same nominal composition in the flame spray (FP) and citrate sol-gel (SG) reactions for the flameless combustion of methane. In addition, Ag's partial substitution of La led to a significant increase in the activity of the catalysts prepared for SG and FP, and the catalytic activity increased with the increase of Ag substitution. Haman Tavakkoli et al.[16] prepared the perovskite-type $\mathrm{LaFe}_{0.9} \mathrm{Co}_{0.1} \mathrm{O}_{3}(\mathrm{LFCO} 1)$ and $\mathrm{LaFe}_{0.1} \mathrm{Co}_{0.9} \mathrm{O}_{3}$ (LFCO2) nanoparticles (NPs). The average particle size is $20-40 \mathrm{~nm}$, to evaluate the ability of the two NPs to remove the pesticide nilium from the aqueous solution; dynamic studies were performed on LFCOs NPs with different exposure time, temperature, initial pesticide concentration and adsorbent dose to find the 
optimal conditions. Results showed the percentage of removal of vitavax by $\mathrm{LFCO}_{2}$ NPs is less than that for $\mathrm{LFCO}_{1}$ NPs under the same conditions. Shahzad Afzal et al.[12] synthesized mesoporous nanocast perovskites $\left(\mathrm{NC}-\mathrm{LaMnO}_{3}\right.$ and $\left.\mathrm{NC}-\mathrm{LaFeO}_{3}\right)$ and applied them in catalytic ozonation of 2-chlorophenol. $\mathrm{NC}-\mathrm{LaMnO}_{3}$ showed good performance in terms of catalytic activity and stability. A stronger interaction between $\mathrm{NC}-\mathrm{LaMnO}_{3}$ and $\mathrm{O}_{3}$ as well as an interfacial electron transfer resulted in enhanced catalytic activity. The B-site metal ion has a great influence on the catalysis of organic compound decomposition.

Based on the researches in the above literatures, the metal ion in B-site of perovskite can be analogous to the active central structure of the metal hydrolase. Therefore, in this study, we have synthesized $\mathrm{LaNiO}_{3}$ and $2 \% \mathrm{~g}-\mathrm{C}_{3} \mathrm{~N}_{4} / \mathrm{LaNiO}_{3}$ by sol-gel method, Perovskite composite oxide was used to simulate the active center structure of the enzyme, carried out $\mathrm{LaNiO}_{3}$ and $2 \% \mathrm{~g}-\mathrm{C}_{3} \mathrm{~N}_{4} / \mathrm{LaNiO}_{3}$ catalyzed PNPP hydrolysis experiment. The model of carboxylesterase (PNPP) was used to study the kinetics of catalytic hydrolysis. We have established the reaction intermediate state complex dynamic model, and calculated the $\mathrm{pH}$-independent rate constant of the pseudo first-order reaction by a reasonable way. Finally we have proposed the reaction mechanism and the proposed mechanism are proved to be correct.

\section{Experimental}

\subsection{Materials and reagents}

$\mathrm{La}\left(\mathrm{NO}_{3}\right)_{3} \cdot 6 \mathrm{H}_{2} \mathrm{O}(\mathrm{P} 99.95 \%), \mathrm{Ni}\left(\mathrm{NO}_{3}\right)_{3} \cdot 2 \mathrm{H}_{2} \mathrm{O}(\mathrm{P} 99.0 \%), \quad \mathrm{Fe}\left(\mathrm{NO}_{3}\right)_{3} \cdot 9 \mathrm{H}_{2} \mathrm{O}(\mathrm{P} 98.5 \%)$, citric acid (P99.5\%), Tris(hydroxymethyl) methyl aminomethane (THAM) (P99.0\%), 
hydrochloric acid (36-38\%), and potassium nitrate (P99.0\%) were obtained from Reagent Company (China). p-nitrophenyl picolinate (PNPP) was prepared and purified according to the literature[17]. The water used in the experimental was deionized water.

\subsection{Preparation}

\subsubsection{Preparation of $\mathrm{LaNiO}_{3}$ and $2 \%$ g- $\mathrm{C}_{3} \mathrm{~N}_{4} / \mathrm{LaNiO}_{3}$}

$\mathrm{LaNiO}_{3}$ was synthesized by the citric acid sol-gel method[18]. $\mathrm{La}\left(\mathrm{NO}_{3}\right)_{3} \cdot 6 \mathrm{H}_{2} \mathrm{O}$, $\mathrm{Ni}\left(\mathrm{NO}_{3}\right)_{2} \cdot 2 \mathrm{H}_{2} \mathrm{O}$ and citric acid were accurately weighed according to the stoichiometric ratio 1:1:2. Firstly, citric acid was dissolved into deionized water as complexing agent, and then $\mathrm{La}\left(\mathrm{NO}_{3}\right)_{3} \cdot 6 \mathrm{H}_{2} \mathrm{O}$ and $\mathrm{Ni}\left(\mathrm{NO}_{3}\right)_{2} \cdot 2 \mathrm{H}_{2} \mathrm{O}$ were added. At the same time, ammonia was added dropwise until $\mathrm{pH}$ was 1 . The mixed solution was heated at $70{ }^{\circ} \mathrm{C}$ in a water bath for $10 \mathrm{~h}$ for the formation of sol. After that, the sol was placed in a blast oven at $120^{\circ} \mathrm{C}$ for $10 \mathrm{~h}$ to obtain the precursor. The precursor was calcined at $400{ }^{\circ} \mathrm{C}$ for $4 \mathrm{~h}$ and then at $700{ }^{\circ} \mathrm{C}$ for $4 \mathrm{~h}$ in the muffle furnace under air.

The $\mathrm{g}-\mathrm{C}_{3} \mathrm{~N}_{4}$ was synthesized by calcination. A certain amount of urea was taken and dried at $80^{\circ} \mathrm{C}$ for 24 hours. The samples were placed in the muffle furnace with programmed temperature rise, and the temperature was set at $200^{\circ} \mathrm{C}$ for $4 \mathrm{~h}, 400^{\circ} \mathrm{C}$ for $2 \mathrm{~h}$, and $550^{\circ} \mathrm{C}$ for $2 \mathrm{~h}$. The temperature rise rate was $5^{\circ} \mathrm{C} / \mathrm{min}$. When the crucible is removed, let it cool to room temperature. The light yellow g- $\mathrm{C}_{3} \mathrm{~N}_{4}$ powder can be prepared in the crucible.

The total mass was $0.01 \mathrm{~g}$. A certain amount of $\mathrm{g}-\mathrm{C}_{3} \mathrm{~N}_{4}$ and a certain amount of $\mathrm{LaNiO}_{3}$ were weighed and dispersed in $10 \mathrm{~mL}$ anhydrous ethanol, respectively. $\mathrm{LaNiO}_{3} /$ ethanol dispersion system was dripped into g- $\mathrm{C}_{3} \mathrm{~N}_{4} /$ ethanol dispersion system while stirring. 
The mixed system was by ultrasound 30 minutes and by stirred at room temperature for 12 hours then transferred to the reaction kettle carefully and placed in the blast drying oven at $120^{\circ} \mathrm{C}$ for $6 \mathrm{~h}$. It was cooled down to room temperature. After centrifugation, it was dried for 12 hours and weighed.

\subsubsection{Preparation of Tris-HCl buffer solution}

A certain amount of Tris was dissolved in deionized water, and then $0.01 \mathrm{~mol} / \mathrm{L} \mathrm{KNO}_{3}$ or $\mathrm{HCl}$ were added until $\mathrm{pH}$ value is $6.5,7,7.3,7.5,7.8 .0 .01 \mathrm{~mol} \cdot \mathrm{L}^{-1}$ Tris- $\mathrm{HCl}$ buffer solution was obtained as a stock solution.

\subsection{Characterization}

In order to characterize the structures, morphologies, and compositions of the samples, the following measurements were conducted. The structures of catalysts were analyzed using X-ray Diffraction (XRD) with $\mathrm{Cu} \mathrm{K \alpha}$ at $\lambda=0.154 \mathrm{~nm}$. The morphologies of the catalysts were examined using Scanning Electron Microscopy

(SEM, Hitachi S-4800). The surface areas were determined by Brunauer-Emmett-Teller (BET).

\subsection{Catalytic activity test}

Catalytic experiments by $\mathrm{LaNiO}_{3}$ were conducted in Tris- $\mathrm{HCl}$ buffer solution at different $\mathrm{pH}(6.5,7,7.3,7.5,7.8) ,.0 .01 \mathrm{~g}$ catalyst was added in $20 \mathrm{ml}$ Tris-HCl buffer solution. Then it was mixed with PNPP solution (concentration is $1 \times 10^{-5}-5 \times 10^{-5} \mathrm{~mol} / \mathrm{L}$ ) prepared with acetonitrile. The suspension was filtered every 10 minutes, injected into a $3 \mathrm{~mL}$ catalyst-containing cuvette with a micro-syringe, and analyzed by the dual-beam ultraviolet-visible (UV-Vis) spectrophotometer with a thermostatic device (TU-1901). 
The reaction rates were followed by monitoring the variation of p-nitrophenol at the wavelength of $400 \mathrm{~nm}$ with time under the conditions of excess of catalyst over substrate (PNPP). The apparent first-order rate constants were obtained on fitting an equation $\left(\ln \left(A_{\mathrm{t}}-A_{\infty}\right)-\ln \left(A_{0}-A_{\infty}\right)=-k_{\text {obsdt }}\right)$ by linear least squares treatment [19] by repeating three times. The standard deviation of the reaction rate is less than $3 \%$.

\section{Results and discussion}

\subsection{Structures and morphologies of the catalysts}

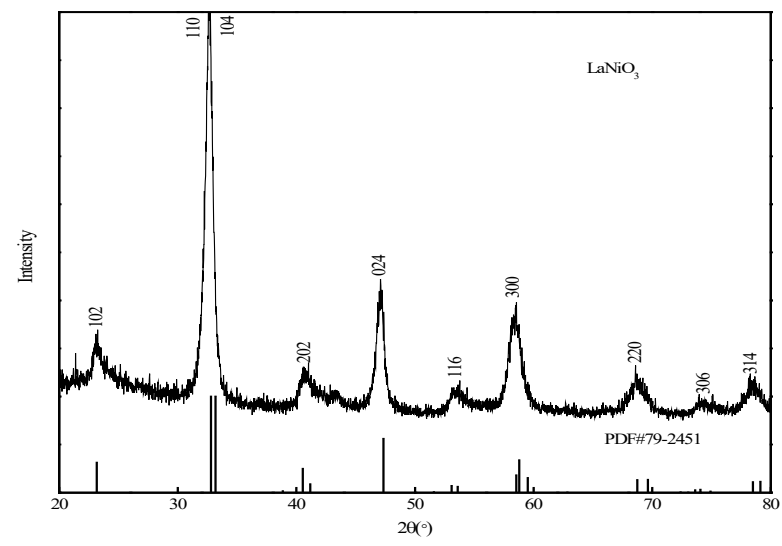

Figure 1 XRD patterns of $\mathrm{LaNiO}_{3}$

Fig. 1. displays the XRD patterns of $\mathrm{LaNiO}_{3}$ obtained from precursor. The characteristic diffraction peaks of $\mathrm{LaNiO}_{3}$ matches perfectly with PDF\#79-2451 with a hexagonal structure. Main peaks correspond to the perovskite phase (102), (110), (104), (202), (024), (116), (300), (220), (306), (314) crystal plane, respectively. There are no additional phases of other impurities. The crystallite size of $\mathrm{LaNiO}_{3}$ was calculated using the XRD peak broadening of the $\left(2 \theta=32.672^{\circ}\right)$ peak by Debye-Scherrer formula[20]: 


$$
\mathrm{D}=\frac{k \lambda}{\beta \cos \theta}
$$

Where $\mathrm{D}(\mathrm{nm})$ is the particle size of $\mathrm{LaNiO}_{3}, \mathrm{k}(\mathrm{nm})$ is the wavelength of $\mathrm{X}$-ray, $\beta$ is the full width at half maximum, and $\theta(\mathrm{Rad})$ is the Bragg angle. The crystallite size of $\mathrm{LaNiO}_{3}$ was about $12 \mathrm{~nm}[21]$.

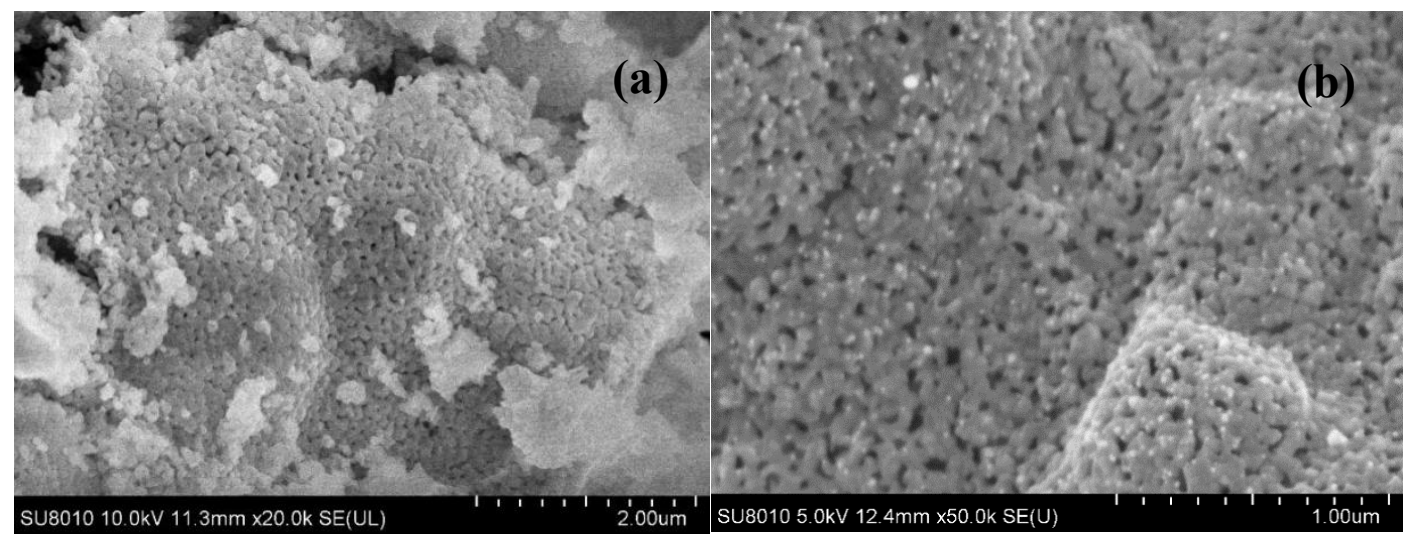

Figure 2 SEM patterns of $\mathrm{LaNiO}_{3}$

Fig. 2. exhibits the SEM patterns of $\mathrm{LaNiO}_{3}$ nanoparticles in compliance with the results of XRD in Fig. 1. These spherical, uniform-sized nanoparticles are agglomerated in large amounts to form a planar network structure, and it is apparent that there are uneven microspores, which help to adsorb PNPP and accelerate the chemical reaction rate.

In figure (a), $\mathrm{LaNiO}_{3}$ is spherical with uniform size, and the particle size is significantly larger than that of the XRD pattern. This is due to the large agglomeration of nanoparticles. During the preparation of $\mathrm{LaNiO}_{3}$, the solution had a high $\mathrm{pH}$ and was not so acidic, which helped perovskite grains to disperse and form a planar and loose network structure, which was conducive to the increase of specific surface area and the increase of contact between PNPP and the catalyst. As shown in figure (b), a large number of holes are distributed on the material plane, with small 
and regular pore sizes, but different pore sizes. These holes can increase the contact between PNPP and the catalyst, adsorb PNPP, and accelerate the catalytic reaction rate.

The $\mathrm{N}_{2}$ isotherm in Fig. 3 (a) corresponds to a type IV isotherm in the IUPAC classification. At moderate relative pressure, the type IV isotherm rises rapidly due to the occurrence of capillary condensation. The characteristic of these curves is their hysteresis loops, and they correspond to a system in which the porous adsorbent exhibiting capillary condensation. According to the IUPAC classification, the loop observed is ascribed to type H3 loops[22], which does not exhibit limiting adsorption at high relative pressures and has no obvious saturated adsorption platform, indicating the presence of irregular microporoes in the material. The surface area was calculated to be $21.277 \mathrm{~m}^{2} / \mathrm{g}$.

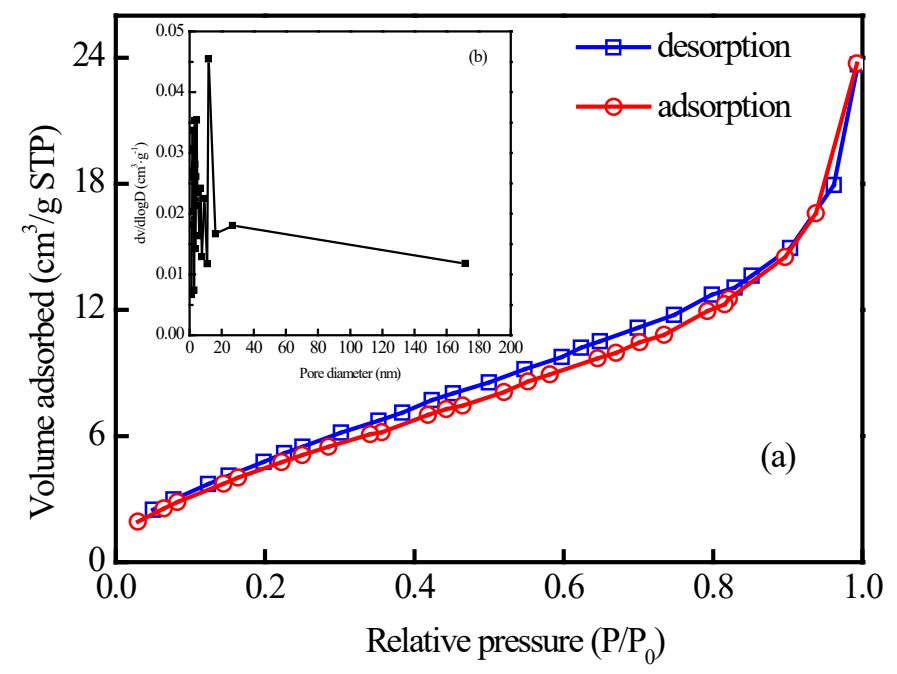

Figure 3 (a) Nitrogen adsorption /desorption isotherms of $\mathrm{LaNiO}_{3}$, (b) pore size distribution determined by the BJH method

Fig. 3 (b) shows the pore size distribution. The pore size was derived from desorption data and calculated from the isotherm using the BJH model. The main size 
of pores ranges from 2 to $10 \mathrm{~nm}$ and the average pore size is $1.839 \mathrm{~nm}$ by calculation, which consists with the results of SEM in Fig. 2.

Many literatures reported that $\mathrm{g}-\mathrm{C}_{3} \mathrm{~N}_{4}$ and perovskite oxides were doped with each other to increase the specific surface area of the catalyst, so as to improve the catalytic efficiency. Can this improve the efficiency of ester hydrolysis? Wt1 \%-10\% g- $\mathrm{C}_{3} \mathrm{~N}_{4} /$ $\mathrm{LaNiO}_{3}$ composite catalyst was prepared by combining simple mechanical stirring with hydrothermal method. We found that the $2 \% \mathrm{~g}-\mathrm{C}_{3} \mathrm{~N}_{4} / \mathrm{LaNiO}_{3}$ composite catalyst had good catalytic effect. So we studied the $2 \%$ g- $\mathrm{C}_{3} \mathrm{~N}_{4} / \mathrm{LaNiO}_{3}$ composite catalyst. In Fig. 4, (a) and (b) are SEM images of different parts of $2 \%$ g- $\mathrm{C}_{3} \mathrm{~N}_{4} / \mathrm{LaNiO}_{3}$ catalyst. In figure (a), although a certain amount of $\mathrm{g}-\mathrm{C}_{3} \mathrm{~N}_{4}$ is doped, most $\mathrm{LaNiO}_{3}$ particles gather together and form a plane, which is conducive to the catalytic reaction, because the doped amount is very small. However, according to figure (b), some $\mathrm{LaNiO}_{3}$ particles are attached to te plane of $\mathrm{g}-\mathrm{C}_{3} \mathrm{~N}_{4}$, which effectively increases the contact area between the catalyst and the substrate molecules and increases the catalytic rate.
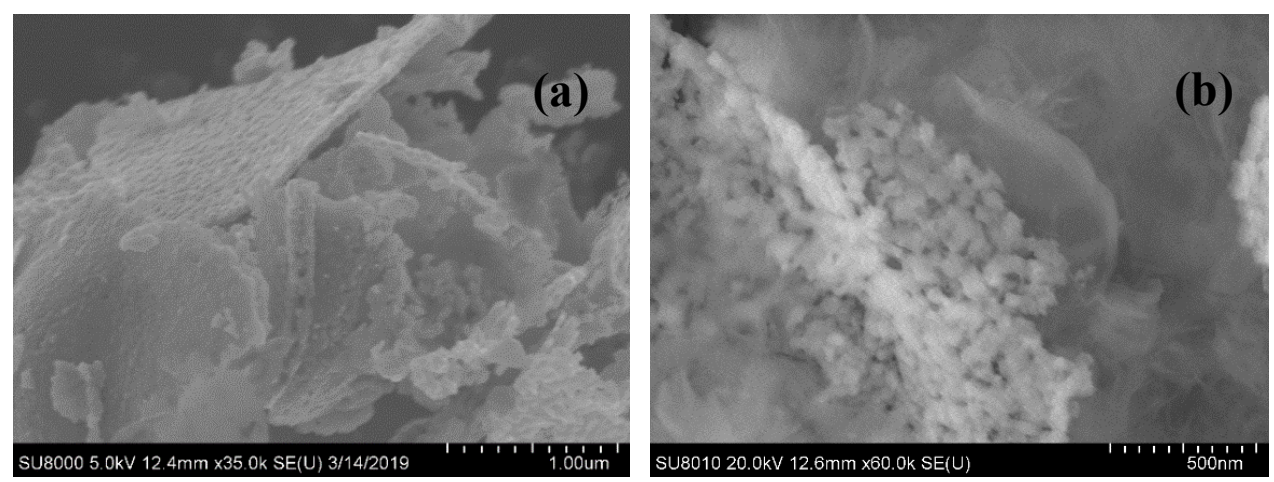

Figure 4 SEM patterns of $2 \%$ g- $\mathrm{C}_{3} \mathrm{~N}_{4} / \mathrm{LaNiO}_{3}$

$\mathrm{N}_{2}$ adsorption and desorption of $2 \% \mathrm{~g}_{-} \mathrm{C}_{3} \mathrm{~N}_{4} / \mathrm{LaNiO}_{3}$ catalyst are shown in Fig. 5. Fig. 5 (a) is $2 \% \mathrm{~g}-\mathrm{C}_{3} \mathrm{~N}_{4} \mathrm{LaNiO}_{3} / \mathrm{N}_{2}$ adsorption - stripping isotherm is similar to 
the isotherm $\mathrm{LaFeO}_{3}$, according to the IUPAC classification, corresponding IV type isotherm, the relative pressure $(\mathrm{P} / \mathrm{P} 0)$ value in the middle section, depending on the presence of isotherm rise suddenly, exist this kind of circumstance is the type IV isotherm, is the result of the occurrence of capillary condensation. Another prominent feature of the type IV isotherm is the presence of adsorption hysteresis in the intermediate segment, which proves to be a porous adsorbent system. H3 type hysteresis ring has no obvious saturated adsorption platform, and shows no adsorption saturation in the area of higher relative pressure, which is a fracture hole material. Through the above analysis, it is shown that $2 \% \mathrm{~g}_{-} \mathrm{C}_{3} \mathrm{~N}_{4} / \mathrm{LaNiO}_{3}$ perovskite composite oxide is a porous adsorption material with irregular pore structure. It is a fissure pore material, and the measured specific surface area is $26.645 \mathrm{~m}^{2} / \mathrm{g}$.

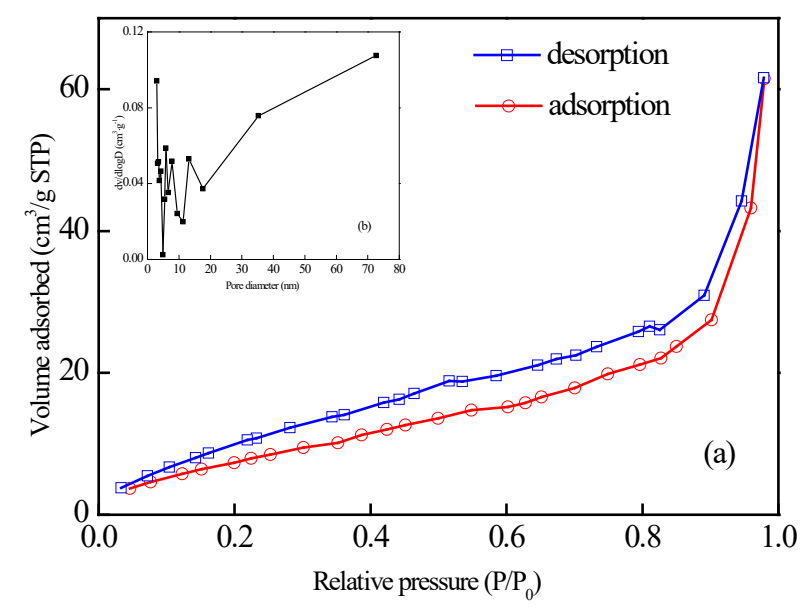

Figure 5 (a) Nitrogen adsorption/desorption isotherms of $2 \%$ g- $\mathrm{C}_{3} \mathrm{~N}_{4} / \mathrm{LaNiO}_{3}$, (b) pore size distribution determined by the BJH method.

Fig. 5 (b) shows the pore size distribution of $2 \% \mathrm{~g}-\mathrm{C}_{3} \mathrm{~N}_{4} / \mathrm{LaNiO}_{3}$. BJH method was used to calculate the pore size obtained during desiccation. Most of the pore sizes were concentrated at $2-10 \mathrm{~nm}$ and the average pore size was $3.013 \mathrm{~nm}$, consistent with the results of SEM. 


\subsection{Apparent rate constants for hydrolysis of $\operatorname{PNPP}(\mathrm{pH}=6.5-8, \mathrm{~T}=298 \mathrm{~K})$}

Catalytic reaction proceeds as described in the experimental section. In the catalytic reaction system, the concentration of PNPP substrate is much larger than the catalyst concentration, so the catalyzing reaction for the decomposition of PNPP can be regarded as a pseudo first-order reaction. Thus, the pseudo first-order apparent rate constant can be calculated according to the rate equation. Table 1 shows the pseudo-first-order rate constants obtained at different $\mathrm{pH}$ values and 298K. Although the rate of PNPP spontaneous hydrolysis in buffer is small, the effects of PNPP spontaneous hydrolysis on the catalytic reaction still need to rule out. As the buffered $\mathrm{pH}$ and concentration increases, the catalytic effect of $\mathrm{LaNiO}_{3}$ increases obviously as shown in Table 1. From this table, the apparent rate constants of $\mathrm{LaNiO}_{3}, k_{\text {obsd }}$, is $0.5726 \mathrm{~min}^{-1}$ at $\mathrm{pH}=7.8, C=5 \times 10^{-5} \mathrm{~mol} / \mathrm{L}$ and $T=298 \mathrm{~K}$.

Table 1 Apparent rate constants $k_{o b s d}\left(\min ^{-1}\right)$ for $\mathrm{LaNiO}_{3}$ hydrolysis of PNPP with different concentration in buffer solution at different $\mathrm{pH}, 298 \mathrm{~K}$

\begin{tabular}{|c|c|c|c|c|}
\hline pH of buffer & $C_{\text {Initial PNPP }} /\left(\times 10^{-5} \mathrm{~mol} / \mathrm{L}\right)$ & $\boldsymbol{k}_{\text {obsd-PNPP Spontaneous Hydrolysis }}$ & $\boldsymbol{k}_{\text {obsd-LaNiO3 }}$ & $k_{\text {obsd }}$ \\
\hline \multirow{5}{*}{6.5} & 1 & 0.004100 & 0.05890 & 0.05480 \\
\hline & 2 & 0.004800 & 0.07570 & 0.07090 \\
\hline & 3 & 0.004500 & 0.08200 & 0.07750 \\
\hline & 4 & 0.005100 & 0.08920 & 0.08410 \\
\hline & 5 & 0.004600 & 0.09700 & 0.09240 \\
\hline \multirow{3}{*}{7} & 1 & 0.01510 & 0.2490 & 0.09800 \\
\hline & 2 & 0.02230 & 0.1543 & 0.1320 \\
\hline & 3 & 0.02170 & 0.1682 & 0.1465 \\
\hline
\end{tabular}




\begin{tabular}{|c|c|c|c|c|}
\hline & 4 & 0.02660 & 0.4195 & 0.1535 \\
\hline & 5 & 0.02820 & 0.4474 & 0.1654 \\
\hline \multirow{5}{*}{7.3} & 1 & 0.05430 & 0.2245 & 0.1702 \\
\hline & 2 & 0.03680 & 0.2597 & 0.2229 \\
\hline & 3 & 0.03020 & 0.2794 & 0.2492 \\
\hline & 4 & 0.03430 & 0.3172 & 0.2829 \\
\hline & 5 & 0.07540 & 0.3706 & 0.2952 \\
\hline \multirow{5}{*}{7.5} & 1 & 0.08020 & 0.2533 & 0.1731 \\
\hline & 2 & 0.08420 & 0.3151 & 0.2309 \\
\hline & 3 & 0.09130 & 0.3740 & 0.2827 \\
\hline & 4 & 0.1013 & 0.4133 & 0.3120 \\
\hline & 5 & 0.1100 & 0.4505 & 0.3405 \\
\hline \multirow{5}{*}{7.8} & 1 & 0.08100 & 0.3259 & 0.2449 \\
\hline & 2 & 0.1116 & 0.4305 & 0.3189 \\
\hline & 3 & 0.1100 & 0.4642 & 0.3542 \\
\hline & 4 & 0.1100 & 0.4999 & 0.3899 \\
\hline & 5 & 0.1492 & 0.5726 & 0.4234 \\
\hline
\end{tabular}

As mentioned above, the optimal catalyst, $2 \% \mathrm{~g}-\mathrm{C}_{3} \mathrm{~N}_{4} / \mathrm{LaNiO}_{3}$, was selected to further study its catalytic kinetics. In the tris- $\mathrm{HCl}$ buffer system under different $\mathrm{pH}$ conditions, $C_{\mathrm{PNPP}}=1 \times 10^{-5}, 2 \times 10^{-5}, 3 \times 10^{-5}, 4 \times 10^{-5}, 4 \times 10^{-5}, 5 \times 10^{-5} \mathrm{~mol} / \mathrm{L}, 298 \mathrm{~K}, C_{\mathrm{Cat}}$ $=0.5 \mathrm{~g} / \mathrm{L}, 2 \% \mathrm{~g}-\mathrm{C}_{3} \mathrm{~N}_{4} / \mathrm{LaNiO}_{3}$ catalyst catalyzed the hydrolysis of PNPP at the pseudo first order apparent rate constant is shown in table2. The self-hydrolysis rate of PNPP 
in buffer solution is very small. However, the effect of self-hydrolysis rate needs to be excluded to ensure the accuracy of experimental results. With the increase of buffer $\mathrm{pH}$ and PNPP concentration, the catalytic efficiency of $2 \%$ g- $\mathrm{C}_{3} \mathrm{~N}_{4} / \mathrm{LaNiO}_{3}$ increased. When $\mathrm{pH}=7.8$, PNPP concentration was $5 \times 10^{-5} \mathrm{~mol} / \mathrm{L}$, and temperature was $298 \mathrm{~K}$, the apparent rate constant $k_{\mathrm{obsd}}$ reached its maximum, and the self-hydrolysis excluding PNPP was $0.6767 \mathrm{~min}^{-1}$.

Table 2 Apparent rate constants $k_{o b s d}\left(\min ^{-1}\right)$ for $2 \%$ g- $\mathrm{C}_{3} \mathrm{~N}_{4} / \mathrm{LaNiO}_{3}$ hydrolysis of PNPP with different concentration in buffer solution at different $\mathrm{pH}, 298 \mathrm{~K}$

\begin{tabular}{|c|c|c|c|c|}
\hline pH of Buffer & $C_{\text {Initial PNPP }} /\left(\times 10^{-5} \mathrm{~mol} / \mathrm{L}\right)$ & $\boldsymbol{k}_{\mathrm{obsd}}$-PNPP Spontaneous Hydrolysis & $k_{\text {obsd }-2 \% \text { g-C3N4/LaNiO3 }}$ & $k_{\text {obsd }}$ \\
\hline \multirow{5}{*}{6.5} & 1 & 0.004100 & 0.07310 & 0.06900 \\
\hline & 2 & 0.004800 & 0.1348 & 0.1300 \\
\hline & 3 & 0.004500 & 0.1645 & 0.1600 \\
\hline & 4 & 0.005100 & 0.2105 & 0.2054 \\
\hline & 5 & 0.004600 & 0.2766 & 0.2720 \\
\hline \multirow{5}{*}{7} & 1 & 0.01510 & 0.1505 & 0.1354 \\
\hline & 2 & 0.02230 & 0.2725 & 0.2502 \\
\hline & 3 & 0.02170 & 0.3292 & 0.3075 \\
\hline & 4 & 0.02660 & 0.3966 & 0.3700 \\
\hline & 5 & 0.02820 & 0.4538 & 0.4256 \\
\hline \multirow{3}{*}{7.3} & 1 & 0.05430 & 0.2316 & 0.1773 \\
\hline & 2 & 0.03680 & 0.3314 & 0.2946 \\
\hline & 3 & 0.03020 & 0.4221 & 0.3919 \\
\hline
\end{tabular}




\begin{tabular}{|c|c|c|c|c|}
\hline & 4 & 0.03430 & 0.5013 & 0.4670 \\
\hline & 5 & 0.07540 & 0.6096 & 0.5342 \\
\hline \multirow{5}{*}{7.5} & 1 & 0.08020 & 0.2845 & 0.2043 \\
\hline & 2 & 0.08420 & 0.4488 & 0.3646 \\
\hline & 3 & 0.09130 & 0.5524 & 0.4611 \\
\hline & 4 & 0.1013 & 0.6044 & 0.5031 \\
\hline & 5 & 0.1100 & 0.6762 & 0.5662 \\
\hline \multirow{5}{*}{7.8} & 1 & 0.08100 & 0.3387 & 0.2577 \\
\hline & 2 & 0.1116 & 0.5455 & 0.4339 \\
\hline & 3 & 0.1100 & 0.6459 & 0.5359 \\
\hline & 4 & 0.1100 & 0.7029 & 0.5929 \\
\hline & 5 & 0.1492 & 0.8259 & 0.6767 \\
\hline
\end{tabular}

\subsection{Reaction mechanism for the catalytic hydrolysis of PNPP}

As shown in Table 1, apparent rate constant of PNPP catalytic hydrolysis by $\mathrm{LaNiO}_{3}$ is greater than the rate of PNPP spontaneous hydrolysis in buffer. It has been reported in the literature that complexes can bind to water molecules and form hydrates[23]. The $\mathrm{N}$ atom on the pyridine ring in the PNPP molecule can coordinate with the metal ion to form a complex that promotes the decomposition of the PNPP molecule[24]. On the basis of the references and the experimental results, the mechanism of the hydrolysis of PNPP catalyzed by perovskite-type oxide catalysts $\mathrm{LaNiO}_{3}$ was proposed in this work.

In order to prove the existence of the complex, the spectral scanning 
(200nm-700nm) of the PNPP-added tris-HCl buffer system was carried out by ultraviolet-visible spectrophotometer. The maximum absorption wavelength of PNPP molecule at $272 \mathrm{~nm}$ and the maximum absorption wavelength of the catalyst was 246nm. After the catalyst was added, the same wavelength spectrum scan was performed at the same time, and the maximum absorption wavelength was blue-shifted. The results are shown in Fig. 6.

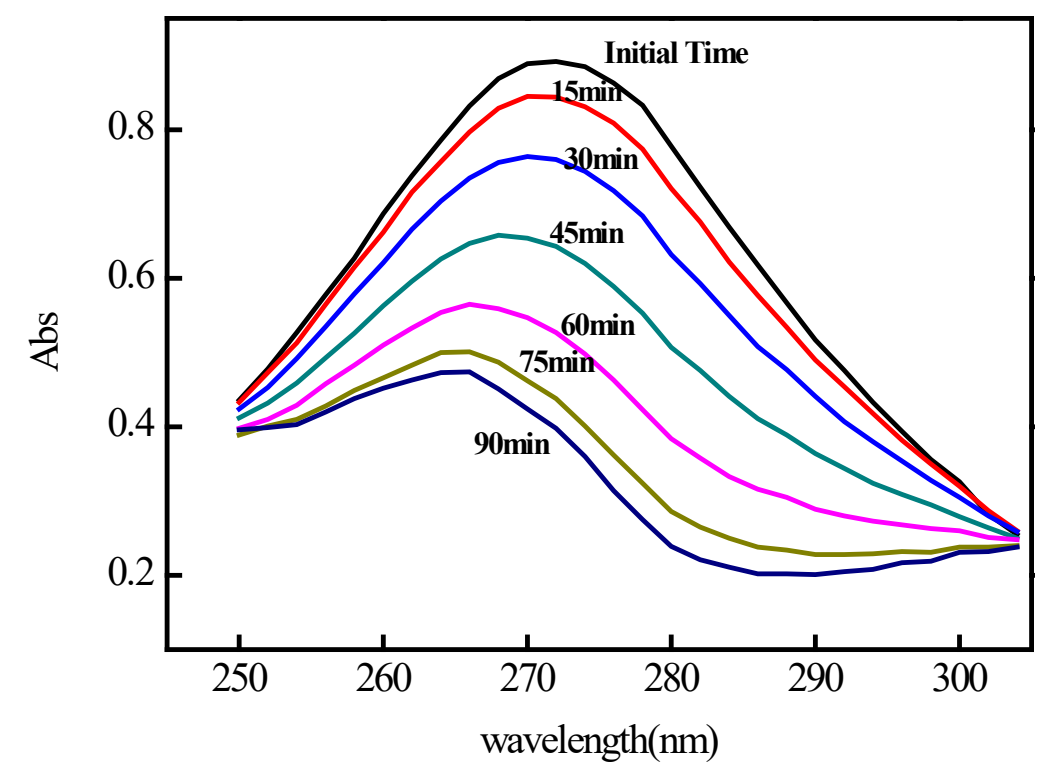

Figure 6 The absorption spectrum at 250-350 nm of PNPP and $\mathrm{LaNiO}_{3}$ mixture

In this figure, the maximum absorption wavelength of PNPP is blue-shifted after the addition of the catalyst, and the maximum absorption wavelength does not change when the PNPP molecule is present in the buffer solution alone. Therefore, it is believed that an intermediate state complex may be formed between the PNPP molecule and $\mathrm{LaNiO}_{3}$, perovskite. The A-site ions in the $\mathrm{LaNiO}_{3}$ type play an important role in maintaining the crystal structure, and the B-site ions have a good coordination effect. The Ni atom at the B-position can coordinate with the atoms in the PNPP 
molecule to form an intermediate state complex, resulting in the change of PNPP structure and then leading to a blue shift in the maximum absorption wavelength of PNPP.

During the catalytic hydrolysis, the PNPP molecule is bind to the surface of the perovskite catalyst to form an intermediate state complex and then the metal ion of the catalyst coordinates to the $\mathrm{N}$ atom of the pyridine ring of PNPP molecule[25]. The formed intermediate state compound in the reaction is beneficial for the intramolecular attack of the $\mathrm{C}$ atom on the PNPP molecule by the hydroxyl radical. It can also accelerate the departure of the product p-nitrophenol, and the catalysis of the PNPP molecule is catalyzed by the intrarmolecular catalytic conversion component instead of intermolecular reaction, which will reduce the energy required for the hydrolytic reaction[25]. Therefore, $\mathrm{LaNiO}_{3}$ can catalyze the decomposition of PNPP efficiently. Metal ions in this catalyst play an important role in this process. One is to disperse the negative charge of the complex, and the other is to activate the water molecules by metal ions, leading to the reactions perform much more easily.

\subsection{Kinetic model of first-order rate constant}




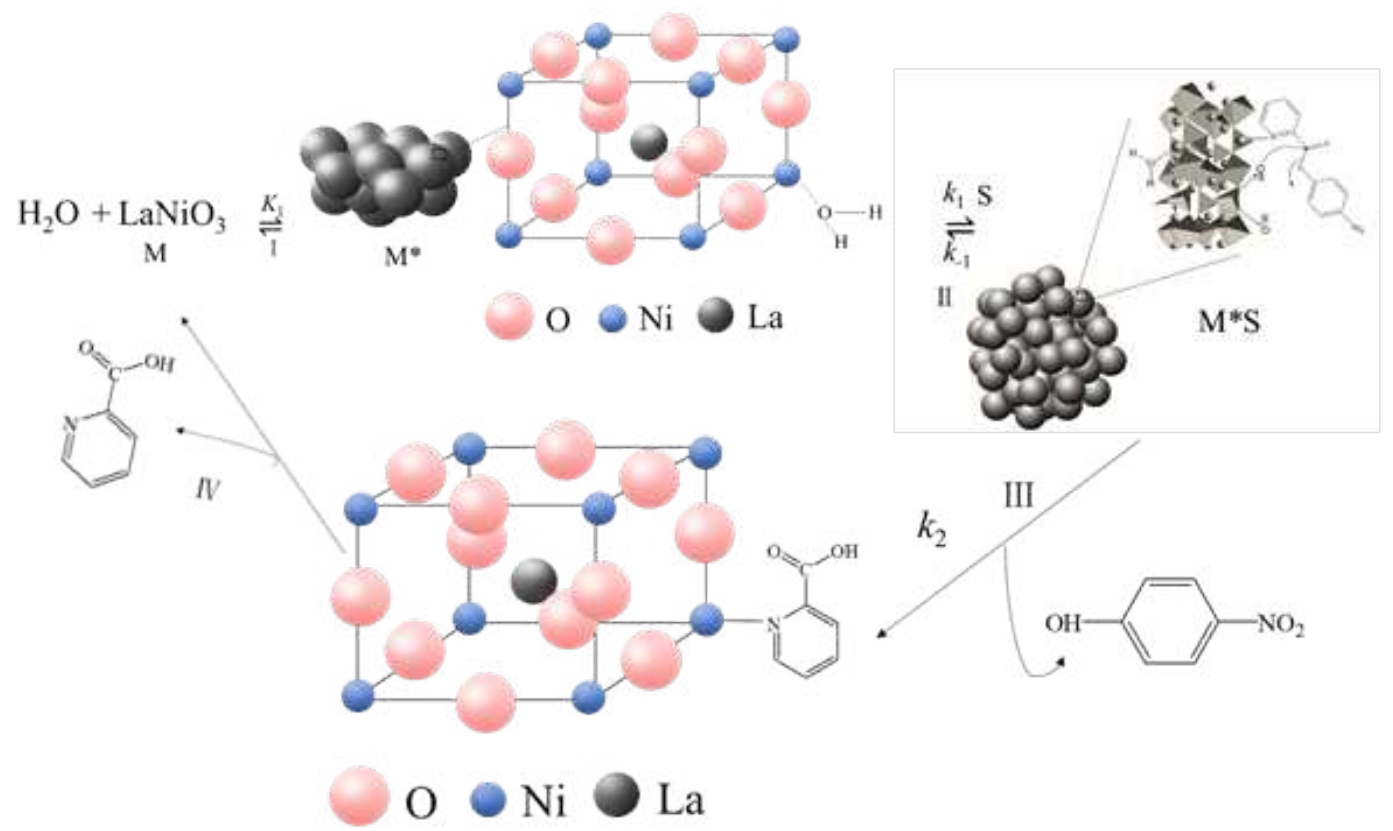

Figure 7 Hydrolysis mechanism of PNPP catalyzed by $\mathrm{LaNiO}_{3}$ nanoparticles

Fig. 7. represents the entire catalytic process. In this figure, $\mathrm{M}$ is $\mathrm{LaNiO}_{3}$ nanoparticles catalyst, $\mathrm{S}$ is the substrate, PNPP, $\mathrm{M} * \mathrm{~S}$ represents the reaction intermediate complex, $\mathrm{P}$ is product, $K_{1}$ represents the association constant of water molecules and catalyst, $k_{2}$ is the pseudo first-order reaction rate constant affected by the $\mathrm{pH}$ of the reaction solution, and $k_{1}$ and $k_{-1}$ are the binding and unbinding constants of the catalyst and the substrate. Fig. 7. shows that $\mathrm{LaNiO}_{3}$ is first combined with water molecules, and then the $\mathrm{N}$ atom on the pyridine ring in the PNPP molecule coordinates to the catalyst, which resulting in the binding of the PNPP molecule to the surface of the perovskite catalyst to form an intermediate complex and the attacking of the hydroxyl radical on $\mathrm{C}$ atom of the carbonyl group to produce $\mathrm{p}$-nitrophenol.

PNPP spontaneous hydrolysis can be ignored because of its relatively low reaction rate. From fig. 7, the rate equation can be expressed:

$$
-\frac{\mathrm{dC}}{\mathrm{dt}}=k_{\text {obsd }}[\mathrm{M}]_{0}=k_{2}\left[\mathrm{M}^{*} \mathrm{~S}\right]
$$


According to the law of chemical equilibrium:

$$
K_{1}^{\prime}=K_{1}\left[\mathrm{H}_{2} \mathrm{O}\right]=\left[\mathrm{M}^{*}\right] /[\mathrm{M}]
$$

$K_{\mathrm{m}[26]}$ from the steady state hypothesis can be determined as follows:

$$
\frac{\left[\mathrm{M}^{*}\right][\mathrm{S}]}{\left[\mathrm{M}^{*} \mathrm{~S}\right]}=\frac{k_{2}+k_{-1}}{k_{1}}=K_{\mathrm{m}}
$$

Combination of equations (2) and (3),

$$
\frac{K_{1}^{\prime}}{K_{\mathrm{m}}}=\frac{\left[\mathrm{M}^{*} \mathrm{~S}\right]}{\left[\mathrm{M}^{*}\right][\mathrm{S}]}
$$

According to the relationship between the concentrations of the catalyst species during the reaction, the following formula can be obtained:

$$
[\mathrm{M}]_{0}=\left[\mathrm{M}^{*}\right]+[\mathrm{M}]+\left[\mathrm{M}^{*} \mathrm{~S}\right]
$$

Combination of equations (3), (4) and (5),

$$
\begin{array}{r}
{[\mathrm{M}]_{0}=\frac{K_{\mathrm{m}}\left[\mathrm{M}^{*} \mathrm{~S}\right]}{K_{1}^{\prime}[\mathrm{S}]}+\left[\mathrm{M}^{*} \mathrm{~S}\right]+\frac{K_{\mathrm{m}}\left[\mathrm{M}^{*} \mathrm{~S}\right]}{[\mathrm{S}]}} \\
{\left[\mathrm{M}^{*} \mathrm{~S}\right]=\frac{[\mathrm{M}]_{0}}{K_{\mathrm{m}} / K_{1}^{\prime}[\mathrm{S}]+1+K_{\mathrm{m}} /[\mathrm{S}]}}
\end{array}
$$

Substituting the formula (7) into the formula (1),

$$
\mathrm{r}=\frac{k_{2}[\mathrm{M}]_{0}}{K_{\mathrm{m}} / K_{1}^{\prime}[\mathrm{S}]+1+K_{\mathrm{m}} /[\mathrm{S}]}=k_{\mathrm{obsd}}[\mathrm{M}]_{0}
$$

Reciprocal on both sides of the equation,

$$
\frac{1}{k_{\text {obsd }}}=\frac{K_{\mathrm{m}}}{k_{2} K_{1}^{\prime}[\mathrm{S}]}+\frac{1}{k_{2}}+\frac{K_{\mathrm{m}}}{k_{2}[\mathrm{~S}]}=\left(\frac{K_{\mathrm{m}}}{k_{2} K_{1}^{\prime}[\mathrm{S}]}+\frac{K_{\mathrm{m}}}{k_{2}}\right) \frac{1}{[\mathrm{~S}]}+\frac{1}{k_{2}}
$$

Defining $1 / K$,

$$
\frac{1}{K}=\frac{K_{\mathrm{m}}}{k_{2} K_{1}^{\prime}[\mathrm{s}]}+\frac{K_{\mathrm{m}}}{k_{2}}
$$

So the final formula we get is 


$$
\frac{1}{k_{\text {obsd }}}=\frac{1}{k_{2}}+\frac{1}{K[\mathrm{~S}]}
$$

In this equation, $k_{2}$ is the pseudo first-order rate constant in dependent of $\mathrm{pH}$. [S] is the initial concentration of PNPP. $k_{\text {obsd }}$ is the observed rate constant of production.

According to the equation (11), $1 / k_{\text {obsd }}$ and $1 /[\mathrm{S}]$ are linear, and $k_{2}$ can be obtained by the slope. The results are shown in Fig. 8(a) and (b), and the results show that $1 / k_{\text {obsd }}$ and $1 /[\mathrm{S}]$ does exhibit a good linear relationship, and the correlation coefficient $\mathrm{r}^{2}>0.99$, which proves that the proposed catalytic mechanism and kinetic model are reasonable.
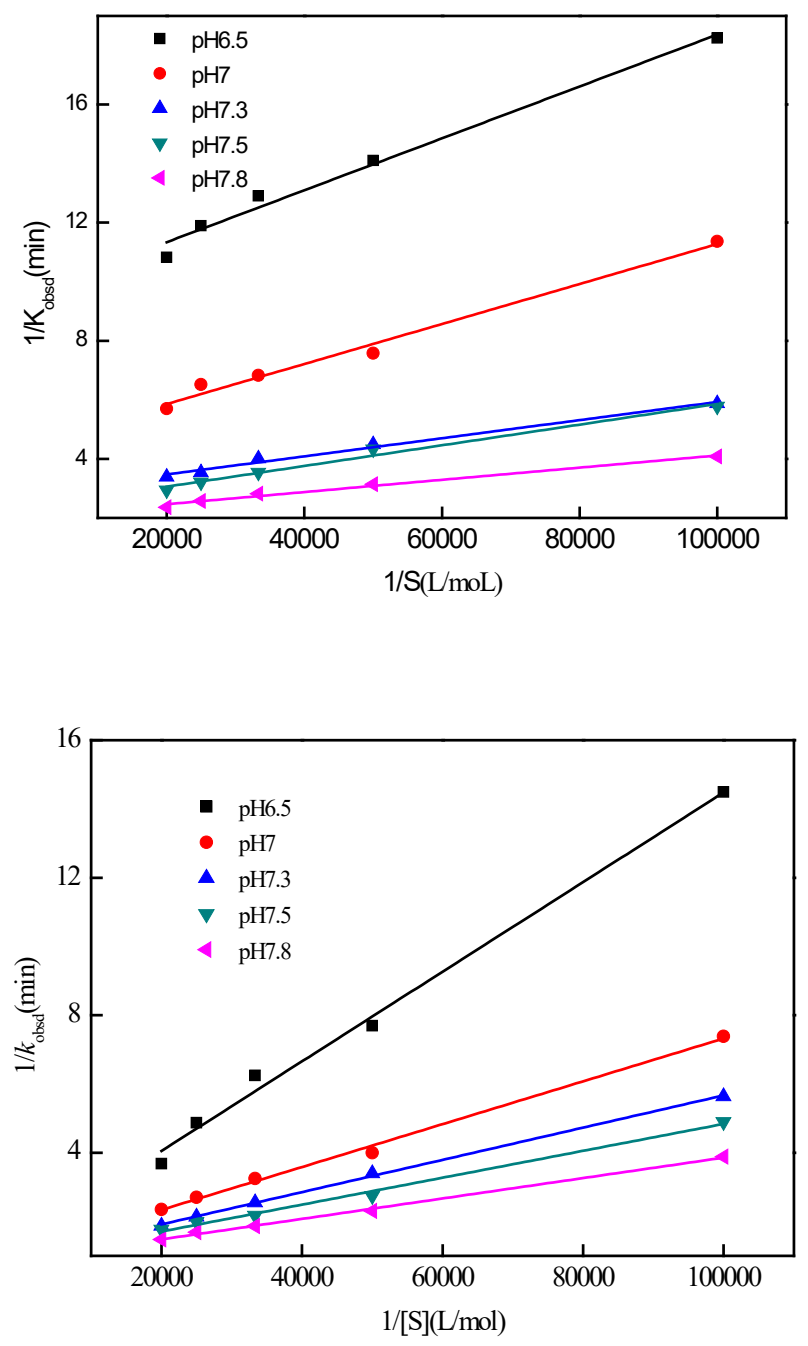

Figure 8 (a)The relationship between $1 / k_{\text {obsd }}$ and $1 /[\mathrm{S}]$ for $\mathrm{LaNiO}_{3}$ catalyzing PNPP in buffer 
with different $\mathrm{pH}$ value, $298 \mathrm{~K}$, Ccat $=0.5 \mathrm{~g} / \mathrm{L}$; (b)The relationship between $1 / \boldsymbol{k}_{\text {obsd }}$ and $1 /[\mathrm{S}]$ for $2 \%$ $\mathrm{g}_{-} \mathrm{C}_{3} \mathrm{~N}_{4} / \mathrm{LaNiO}_{3}$ catalyzing PNPP in buffer with different $\mathrm{pH}$ value, $298 \mathrm{~K}$, Ccat $=0.5 \mathrm{~g} / \mathrm{L}$.

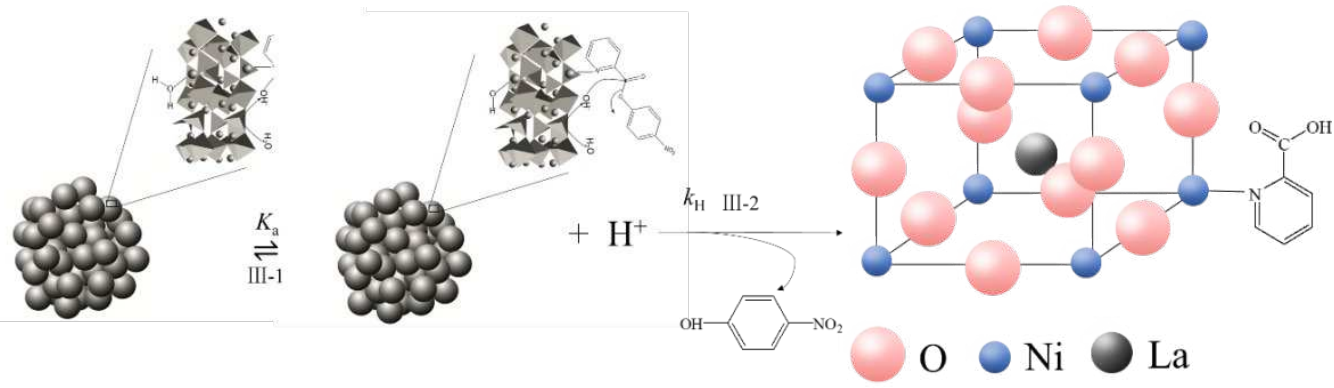

Figure 9 Acidity effect on the catalytic hydrolysis of PNPP

\subsection{Acidity effect on the catalytic hydrolysis of PNPP}

Table $3 k_{2}\left(\mathrm{~min}^{-1}\right)$ of product formation in buffer solution at different $\mathrm{pH}, 298 \mathrm{~K}$

\begin{tabular}{cccccc}
\hline $\mathbf{p H}$ & $\mathbf{6 . 5}$ & $\mathbf{7}$ & $\mathbf{7 . 3}$ & $\mathbf{7 . 5}$ & $\mathbf{7 . 8}$ \\
\hline $\boldsymbol{k}_{\mathbf{2}}\left(\mathrm{LaNiO}_{3}\right)$ & 9.5780 & 4.503 & 2.858 & 2.358 & 2.050 \\
$\boldsymbol{k}_{\mathbf{2}}\left(\mathbf{g}-\mathrm{C}_{\mathbf{3}} \mathrm{N}_{\mathbf{4}} / \mathrm{LaNiO}_{3}\right)$ & 1.442 & 1.091 & 0.9783 & 0.9253 & 0.8866 \\
\hline
\end{tabular}

Table 3 indicates that the acidity of the buffer solution has an effect on the pseudo first-order reaction rate constant $k \mathrm{H}$. The possible reason is shown in Fig. 9. When $\mathrm{pH}$ is 7.8 , the water molecules are easily dissociated to form a negatively charged intermediate state, which will speed up the removal of the product p-nitrophenol, and then accelerate the hydrolytic reaction. In Figure 10, $K_{\mathrm{a}}$ represents the acid ionization equilibrium constant, and $k_{\mathrm{H}}$ is the pseudo first-order reaction rate constant independent of the hydrogen ion concentration. The following equation was applied in order to obtain the pseudo first-order reaction rate constant that is not affected by $\left[\mathrm{H}^{+}\right]$. The relationship between $k_{\mathrm{H}}$ and $k_{2}$ can be expressed by the following formula (12). 


$$
\frac{1}{k_{2}}=\frac{1}{k_{\mathrm{H}}}+\frac{\left[\mathrm{H}^{+}\right]}{\left(k_{\mathrm{H}} K_{\mathrm{a}}\right)}
$$

In this equation, $K_{\mathrm{a}}$ is acid dissociation equilibrium constant. $k_{\mathrm{H}}$ is pseudo first-order reaction rate constant independent of $\mathrm{pH} .\left[\mathrm{H}^{+}\right]$can obtain from $\mathrm{pH}$ value.

According to Table 3 and Fig. $10, k_{\mathrm{H}}$ and $K_{\mathrm{a}}$ are calculated to be $0.59\left(\mathrm{~min}^{-1}\right)$ and $6.67 \times 10^{-8}$, respectively.

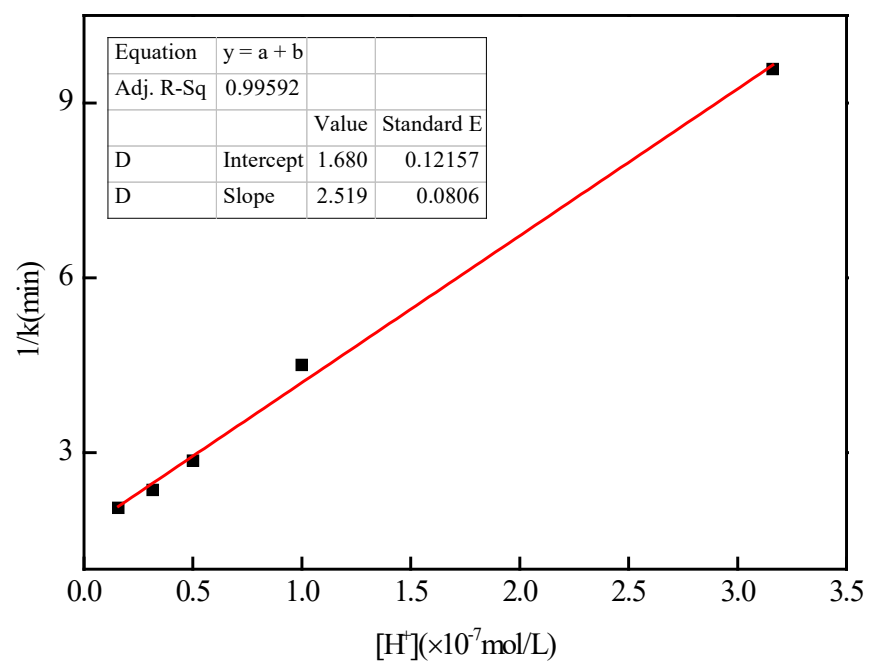

Figure 10 The relationship between $1 / k$ and $\left[\mathrm{H}^{+}\right], 298 \mathrm{~K}, \mathrm{Ccat}=0.5 \mathrm{~g} / \mathrm{L}$

According to Table 3 and Fig. $11, k_{\mathrm{H}}$ and $K_{\mathrm{a}}$ are calculated to be $1.14\left(\mathrm{~min}^{-1}\right)$ and $1.08 \times 10^{-7}$, respectively. 


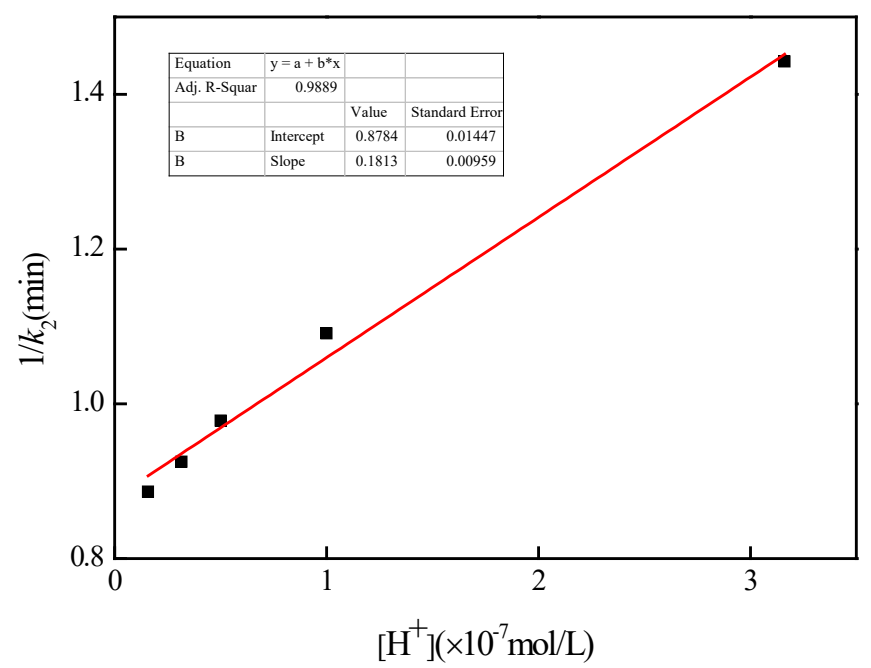

Figure 11 The relationship between $1 / k_{2}$ and $\left[\mathrm{H}^{+}\right], 298 \mathrm{~K}$, Ccat $=0.5 \mathrm{~g} / \mathrm{L}$

The stability of $\mathrm{LaNiO}_{3}$ is investigated in Fig. 12. After 3 continuous hydrolysis cycles, the catalytic activity of $\mathrm{LaNiO}_{3}$ remained essentially unchanged. After the test, it was slightly lowered. However, it has no effect on $\mathrm{LaNiO}_{3}$-catalyst stabilization.

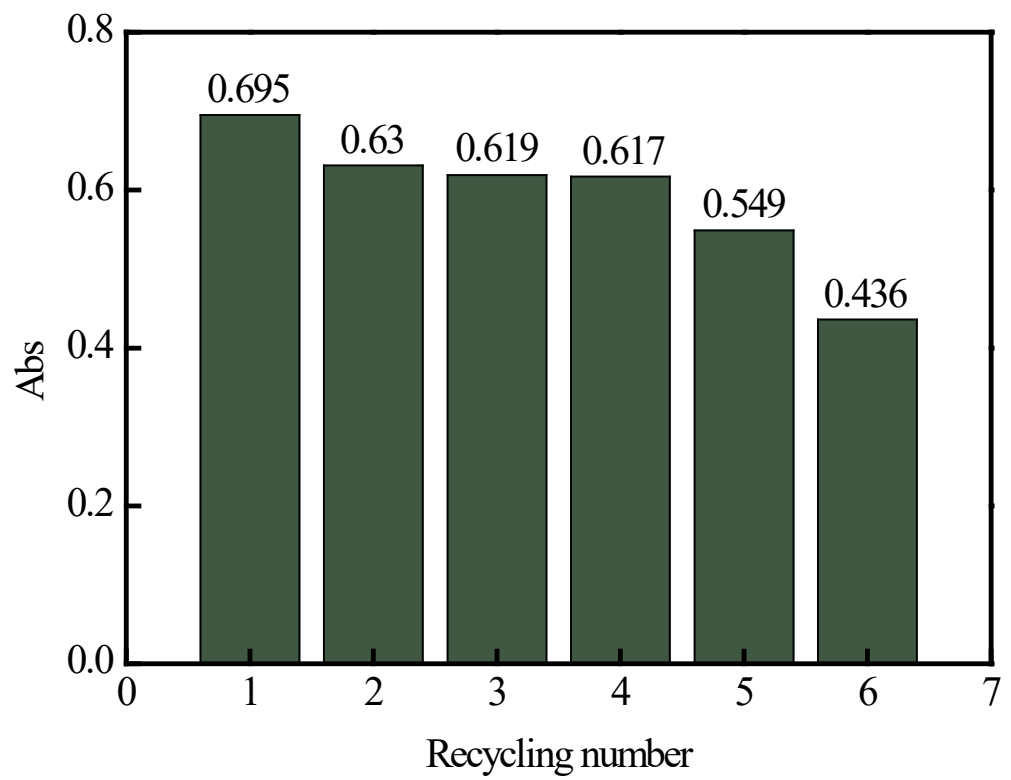

Figure 12 The stability test of PNPP catalytic hydrolysis efficiency by $\mathrm{LaNiO}_{3}$.

\section{Conclusion}

In this work, we have studied hydrolysis of PNPP catalyzed by $\mathrm{LaNiO}_{3}$ and $2 \%$ 
g- $\mathrm{C}_{3} \mathrm{~N}_{4} / \mathrm{LaNiO}_{3}$ and the conclusions are summarized as follows: (1) perovskite-type oxides $\mathrm{LaNiO}_{3}$ and $2 \%$ g- $\mathrm{C}_{3} \mathrm{~N}_{4} / \mathrm{LaNiO}_{3}$ nanoparticles were synthesized using a citric acid sol-gel-calcination method; (2) the proposed reaction mechanism in this work has been confirmed by spectrum and kinetic calculations; (3) perovskite-type oxides $\mathrm{LaNiO}_{3}$ exhibited good catalytic activity and stability to catalyze the hydrolysis of PNPP; (4) the pseudo first-order reaction rate constant of $\mathrm{LaNiO}_{3}$ and $2 \%$ $\mathrm{g}-\mathrm{C}_{3} \mathrm{~N}_{4} / \mathrm{LaNiO}_{3}$ independent of $\mathrm{pH}$ is 0.59 and $1.14 \mathrm{~min}^{-1}$, respectively. This result indicates that we have not found the ideal doped ratio, which will be the goal of our future research.

In this paper, inorganic enzyme was used to simulate carboxypeptidase to catalyze PNPP. Although the reaction rate could not be compared with the decomposition rate of micelle system, the decomposition rate was much higher than the self-hydrolysis of PNPP. In recent years, the inorganic enzymes proposed by scientists have given us a lot of enlightenment and confidence, and we believe that other methods can be used to further improve the reaction rate in future studies.

\section{Availability of data and materials}

Not applicable.

\section{Competing interests}

The authors declare that they have no competing interests.

\section{Funding}

Not applicable. 


\section{Authors' contributions}

Changyu Ye was the main author of the work, performed syntheses, and coordinated all characterization and catalytic studies. Ruiwang was responsible for electron microscopy, Haoyu Wang for BET test, Huixing Zhang and Fubin Jiang assisted with manuscript writing. All authors read and approved the final manuscript.

\section{Acknowledgements}

Not applicable.

\section{Uncategorized References}

1. Wolfenden R, Snider MJ: The depth of chemical time and the power of enzymes as catalysts. Accounts of Chemical Research 2001, 34(12):938-945.

2. Garcia-Viloca M, Gao J, Karplus M, Truhlar DG: How enzymes work: Analysis by modern rate theory and computer simulations. Science 2004, 303(5655):186-195.

3. $\mathrm{Xu} \mathrm{B}$, Jiang $\mathrm{W}$, Liu $\mathrm{X}$, Liu $\mathrm{F}$, Xiang $\mathrm{Z}$ : Remarkable reactivity of alkoxide/acetato-bridged binuclear copper(II) complex as artificial carboxylesterase. Journal of Biological Inorganic Chemistry 2017, 22(4):625-635.

4. Huang X-L: Hydrolysis of Phosphate Esters Catalyzed by Inorganic Iron Oxide Nanoparticles Acting as Biocatalysts. Astrobiology 2018, 18(3):294-310.

5. Zhu J, Li H, Zhong L, Xiao P, Xu X, Yang X, Zhao Z, Li J: Perovskite 
Oxides: Preparation, Characterizations, and Applications in Heterogeneous Catalysis. Acs Catalysis 2014, 4(9):2917-2940.

6. Chen Q, De Marco N, Yang Y, Song T-B, Chen C-C, Zhao H, Hong Z, Zhou H, Yang Y: Under the spotlight: The organic-inorganic hybrid halide perovskite for optoelectronic applications. Nano Today 2015, 10(3):355-396.

7. Guo F, Azimi H, Hou Y, Przybilla T, Hu M, Bronnbauer C, Langner S, Spiecker E, Forberich K, Brabec CJ: High-performance semitransparent perovskite solar cells with solution-processed silver nanowires as top electrodes. Nanoscale 2015, 7(5):1642-1649.

8. Eperon GE, Bryant D, Troughton J, Stranks SD, Johnston MB, Watson T, Worsley DA, Snaith HJ: Efficient, Semitransparent Neutral-Colored Solar Cells Based on Microstructured Formamidinium Lead Trihalide Perovskite. Journal of Physical Chemistry Letters 2015, 6(1):129-138.

9. Huo R, Yang $\mathrm{X}-\mathrm{L}$, Liu Y-Q, Xu Y-H: Visible-light photocatalytic degradation of glyphosate over BiVO4 prepared by different co-precipitation methods. Materials Research Bulletin 2017, 88:56-61.

10. He G-L, Zhong Y-H, Chen M-J, Li X, Fang Y-P, Xu Y-H: One-pot hydrothermal synthesis of SrTiO3-reduced graphene oxide composites with enhanced photocatalytic activity for hydrogen production. Journal of Molecular Catalysis a-Chemical 2016, 423:70-76.

11. Mao J, Quan X, Wang J, Gao C, Chen S, Yu H, Zhang Y: Enhanced 
heterogeneous Fenton-like activity by $\mathrm{Cu}$-doped $\mathrm{BiFeO3}$ perovskite for degradation of organic pollutants. Frontiers of Environmental Science \& Engineering 2018, 12(6).

12. Afzal S, Quan X, Zhang JL: High surface area mesoporous nanocast LaMO3 $(\mathrm{M}=\mathrm{Mn}, \mathrm{Fe})$ perovskites for efficient catalytic ozonation and an insight into probable catalytic mechanism. Applied Catalysis B-Environmental 2017, 206:692-703.

13. Ullmann $\mathrm{H}$, Trofimenko $\mathrm{N}$ : Estimation of effective ionic radii in highly defective perovskite-type oxides from experimental data. Journal of Alloys and Compounds 2001, 316(1-2):153-158.

14. Mahzoon S, Nowee SM, Haghighi M: Synergetic combination of 1D-2D g-C3N4 heterojunction nanophotocatalyst for hydrogen production via water splitting under visible light irradiation. Renewable Energy 2018, 127:433-443.

15. Buchneva O, Rossetti I, Oliva C, Scavini M, Cappelli S, Sironi B, Allieta M, Kryukov A, Forni L: Effective Ag doping and resistance to sulfur poisoning of La-Mn perovskites for the catalytic flameless combustion of methane. Journal of Materials Chemistry 2010, 20(44):10021-10031.

16. Tavakkoli H, Yazdanbakhsh M: Fabrication of two perovskite-type oxide nanoparticles as the new adsorbents in efficient removal of a pesticide from aqueous solutions: Kinetic, thermodynamic, and adsorption studies. Microporous and Mesoporous Materials 2013, 176:86-94. 
17. Sigman DS, Jorgensen CT: Models for metalloenzymes. The zinc(II)-catalyzed transesterification of N-( -hydroxyethyl) ethylenediamine by p-nitrophenyl picolinate. Journal of the American Chemical Society 1972, 94(5):1724-1730.

18. Radhakrishna I KN, A.S. Lakshmanan: Bulletin of Electrochemistry 1993, 9:324-325.

19. Li J-Z, Huang S-T, Feng F-M, Xu B, Jiang W-D, Zeng X-C, Qin S-Y: Studies on p-Nitrophenyl Picolinate (PNPP) Cleavage by Mono-Schiff Base Complexes with Aza-Crown Ether or Morpholino Pendants in CTAB Micellar Solution. Journal of Dispersion Science and Technology 2009, 30(5):656-663.

20. Katz L: Interpretation of X-Ray Powder Diffraction Patterns(Lipson, H; Steeple, H). Journal of Chemical Education 1971, 48(9):A564-.

21. Rivas ME, Hori CE, Fierro JLG, Goldwasser MR, Griboval-Constant A: H-2 production from $\mathrm{CH} 4$ decomposition: Regeneration capability and performance of nickel and rhodium oxide catalysts. Journal of Power Sources 2008, 184(1):265-275.

22. Lv T, Wu MH, Guo MX, Liu Q, Jia LS: Self-assembly photocatalytic reduction synthesis of graphene-encapusulated $\mathrm{LaNiO3}$ nanoreactor with high efficiency and stability for photocatalytic water splitting to hydrogen. Chemical Engineering Journal 2019, 356:580-591.

23. Li JZ, Xie JQ, Zeng W, Wei XY, Zhou B, Zeng XC, Qin SY: Cobalt(II) Schiff 
base complexes bearing aza crown ether pendants as synthetic hydrolase catalyzing PNPP hydrolysis. Transition Metal Chemistry 2004, 29(5):488-494.

24. Xiang Y, Jiang BY, Zeng XC, Xie JQ: Metallomicellar catalysis: Catalytic cleavage of p-nitrophenyl picolinate by $\mathrm{Cu} 2+$ complex of 4-chloride-2,6-bis(N-hydroxyethylaminomethyl)benzophenol in micellar solution. Journal of Colloid and Interface Science 2002, 247(2):366-371.

25. Xie B, Xie JQ, Feng XS, Zhang CX, Zeng XC: Synthesis of two Schiff base transition metal complexes bearing morpholine side chains and kinetics of PNPP catalytic hydrolysis in Brij35 micelle. Journal of Dispersion Science and Technology 2007, 28(6):920-926.

26. Borstlap AC, Doucet PG: The 'double' Michaelis-Menten equation: estimation of parameters. Zeitschrift fur Naturforschung Section C, Biosciences 1983, 38(3-4):268-272. 
Figures

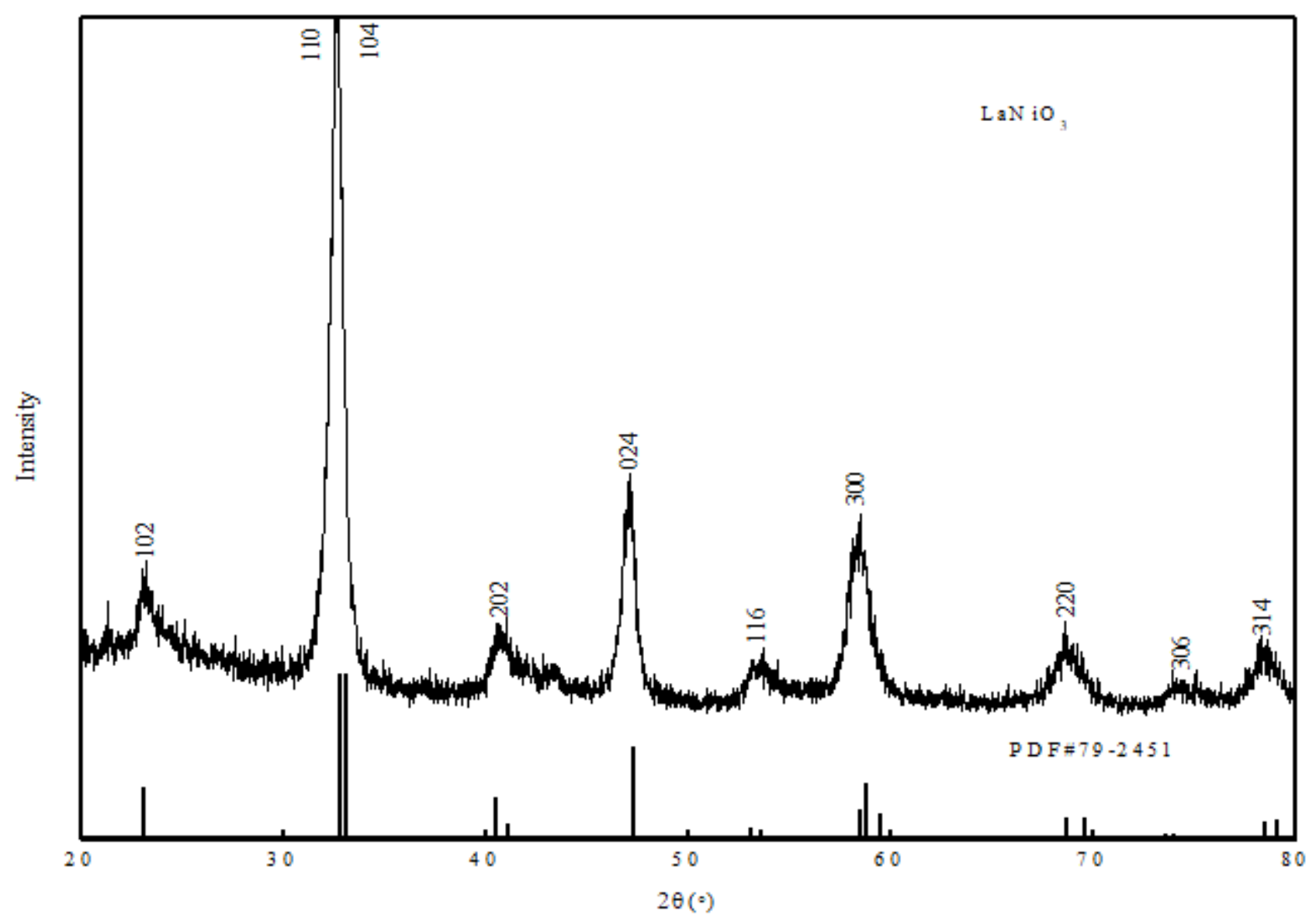

Figure 1

XRD patterns of $\mathrm{LaNiO3}$

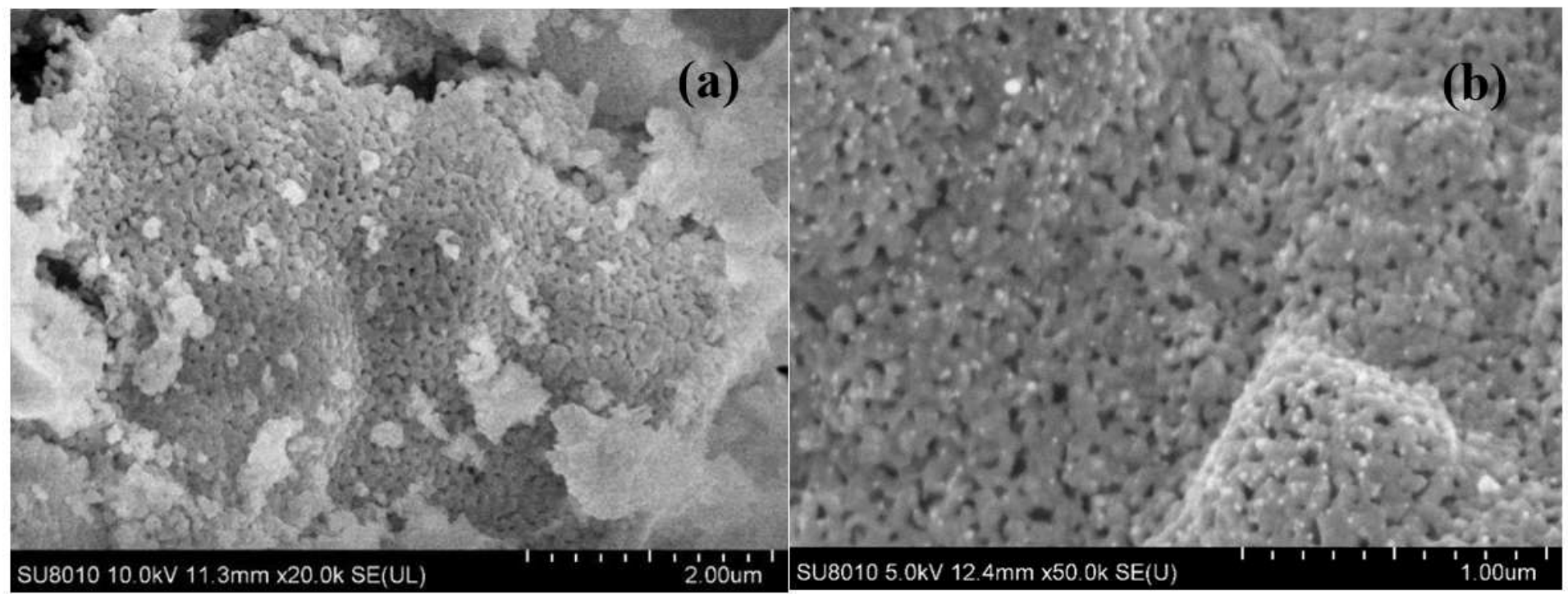

Figure 2 


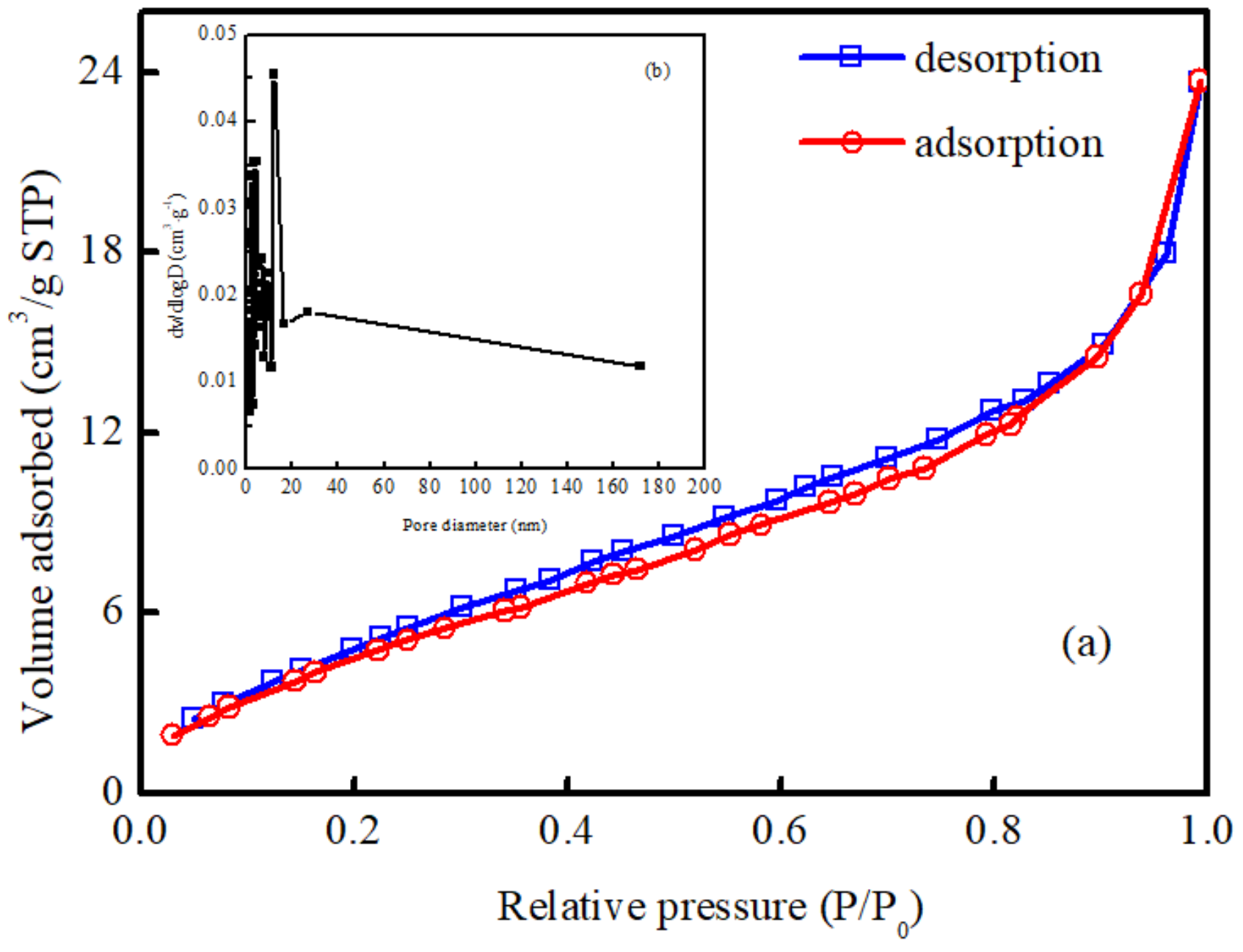

Figure 3

(a) Nitrogen adsorption /desorption isotherms of $\mathrm{LaNiO3,} \mathrm{(b)} \mathrm{pore} \mathrm{size} \mathrm{distribution} \mathrm{determined} \mathrm{by} \mathrm{the} \mathrm{BJH}$ method
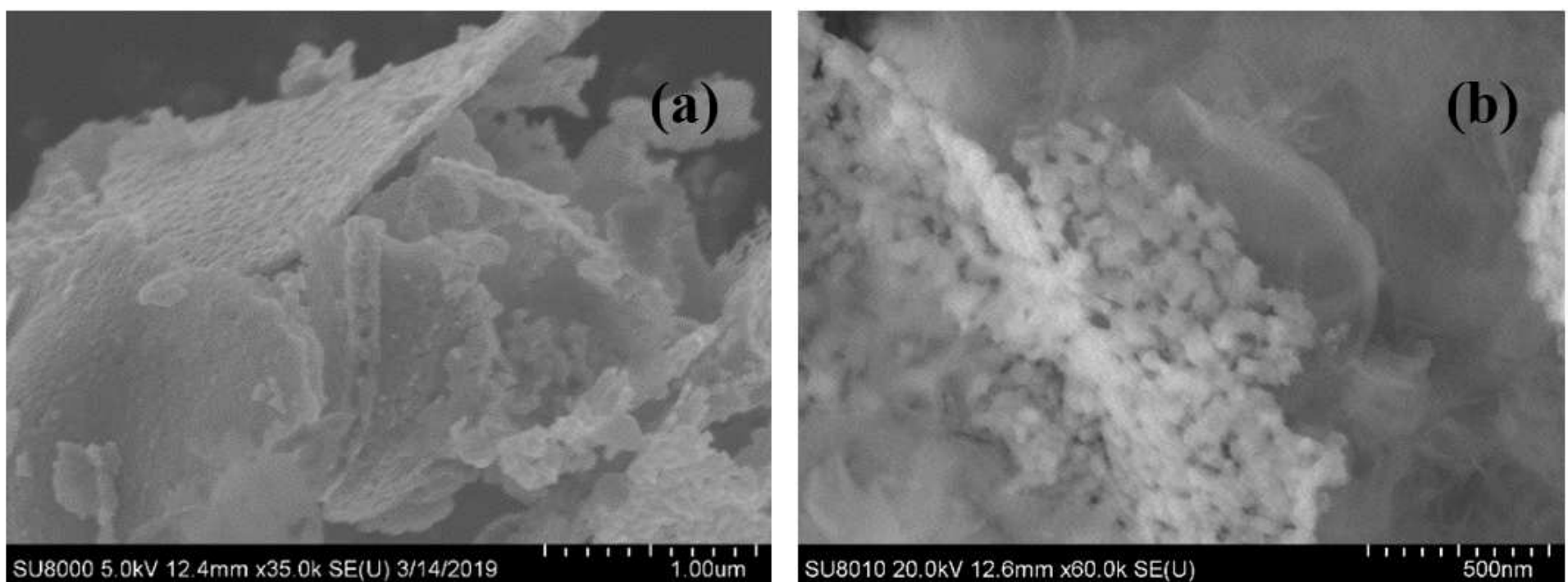
Figure 4

SEM patterns of $2 \% \mathrm{~g}-\mathrm{C} 3 \mathrm{~N} 4 / \mathrm{LaNiO} 3$

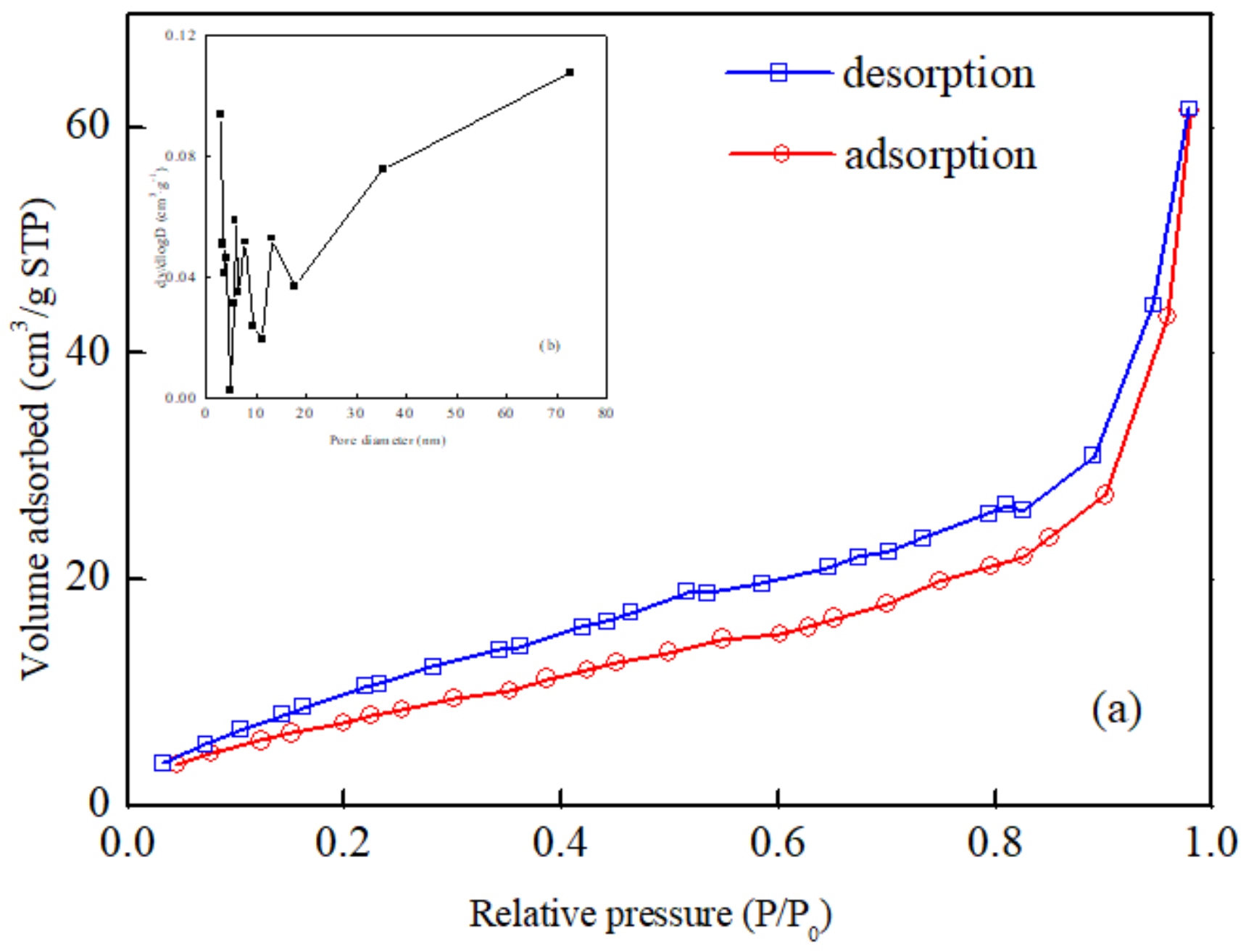

Figure 5

(a) Nitrogen adsorption/desorption isotherms of 2\% g-C3N4 / LaNiO3, (b) pore size distribution determined by the BJH method. 


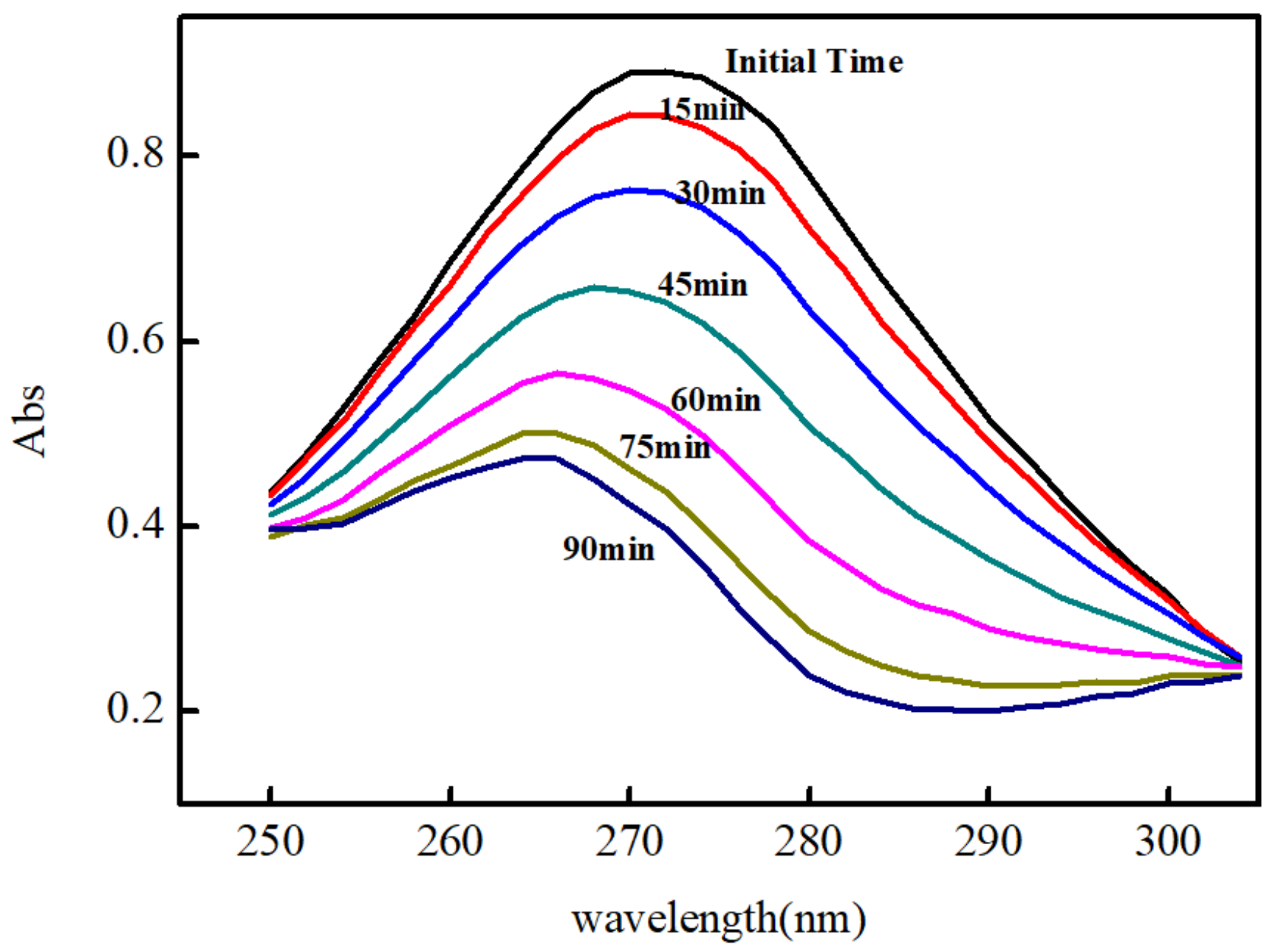

Figure 6

The absorption spectrum at $250-350 \mathrm{~nm}$ of PNPP and LaNiO3 mixture 


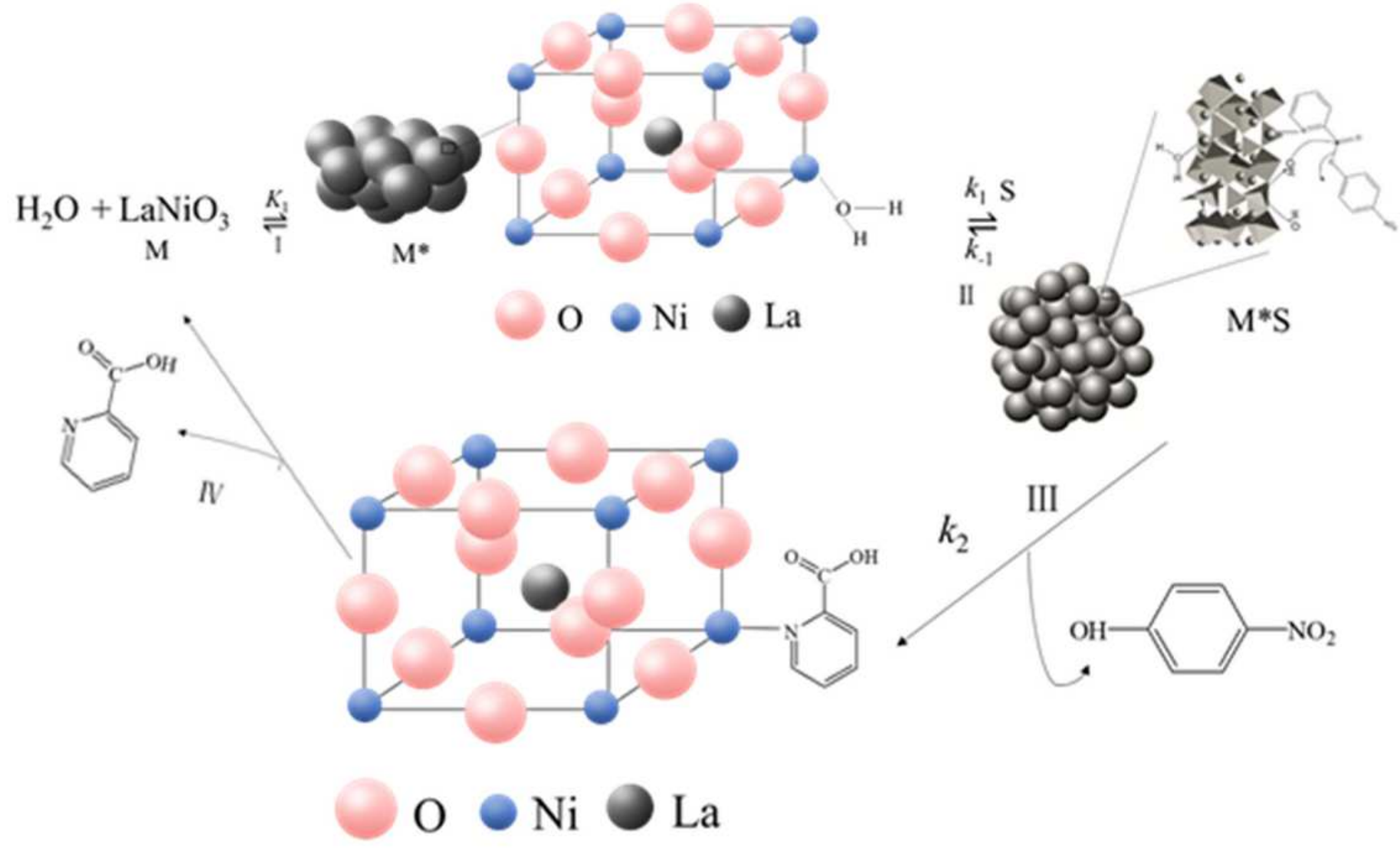

Figure 7

Hydrolysis mechanism of PNPP catalyzed by LaNiO3 nanoparticles 

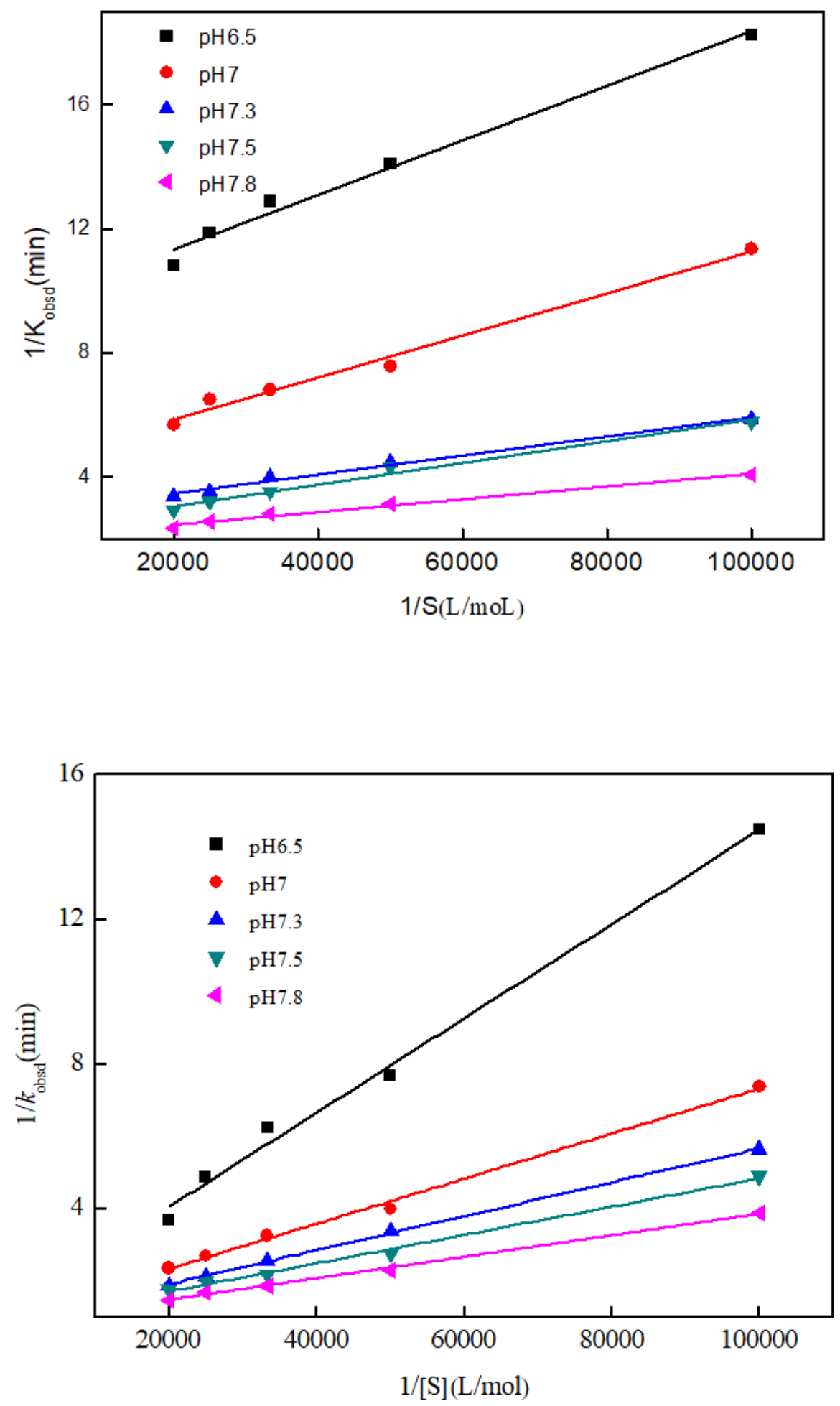

Figure 8

(a)The relationship between 1/kobsd and 1/[S] for LaNiO3 catalyzing PNPP in buffer with different $\mathrm{pH}$ value, $298 \mathrm{~K}$, Ccat $=0.5 \mathrm{~g} / \mathrm{L}$; (b)The relationship between 1/kobsd and 1/[S] for $2 \% \mathrm{~g}-\mathrm{C} 3 \mathrm{~N} 4 / \mathrm{LaNiO} 3$ catalyzing PNPP in buffer with different $\mathrm{pH}$ value, $298 \mathrm{~K}$, Ccat $=0.5 \mathrm{~g} / \mathrm{L}$. 


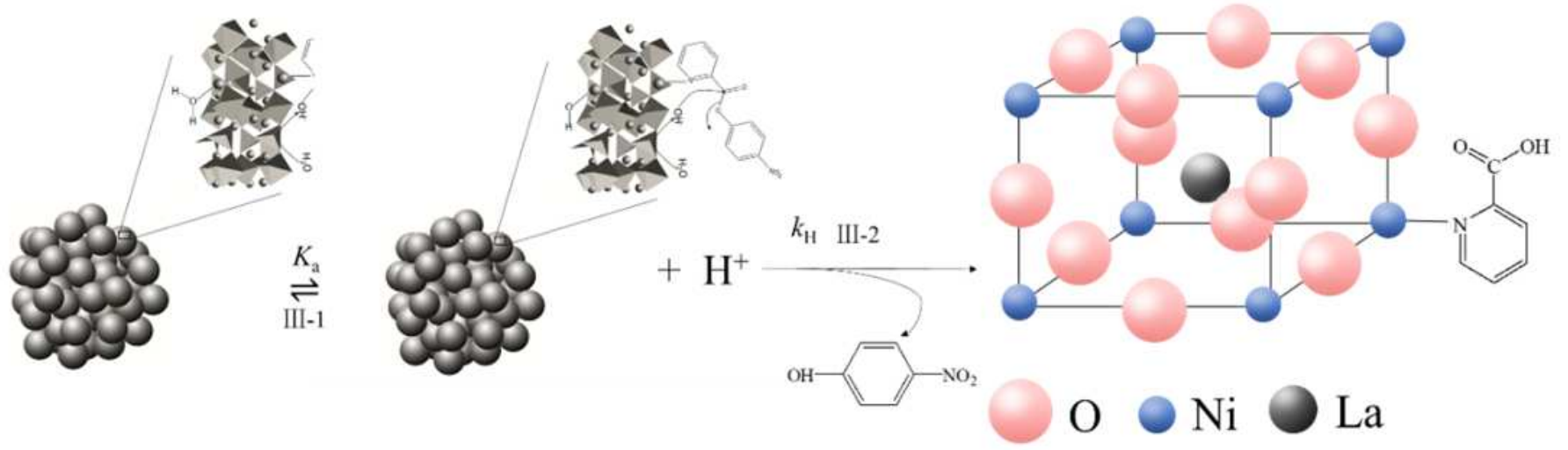

Figure 9

Acidity effect on the catalytic hydrolysis of PNPP

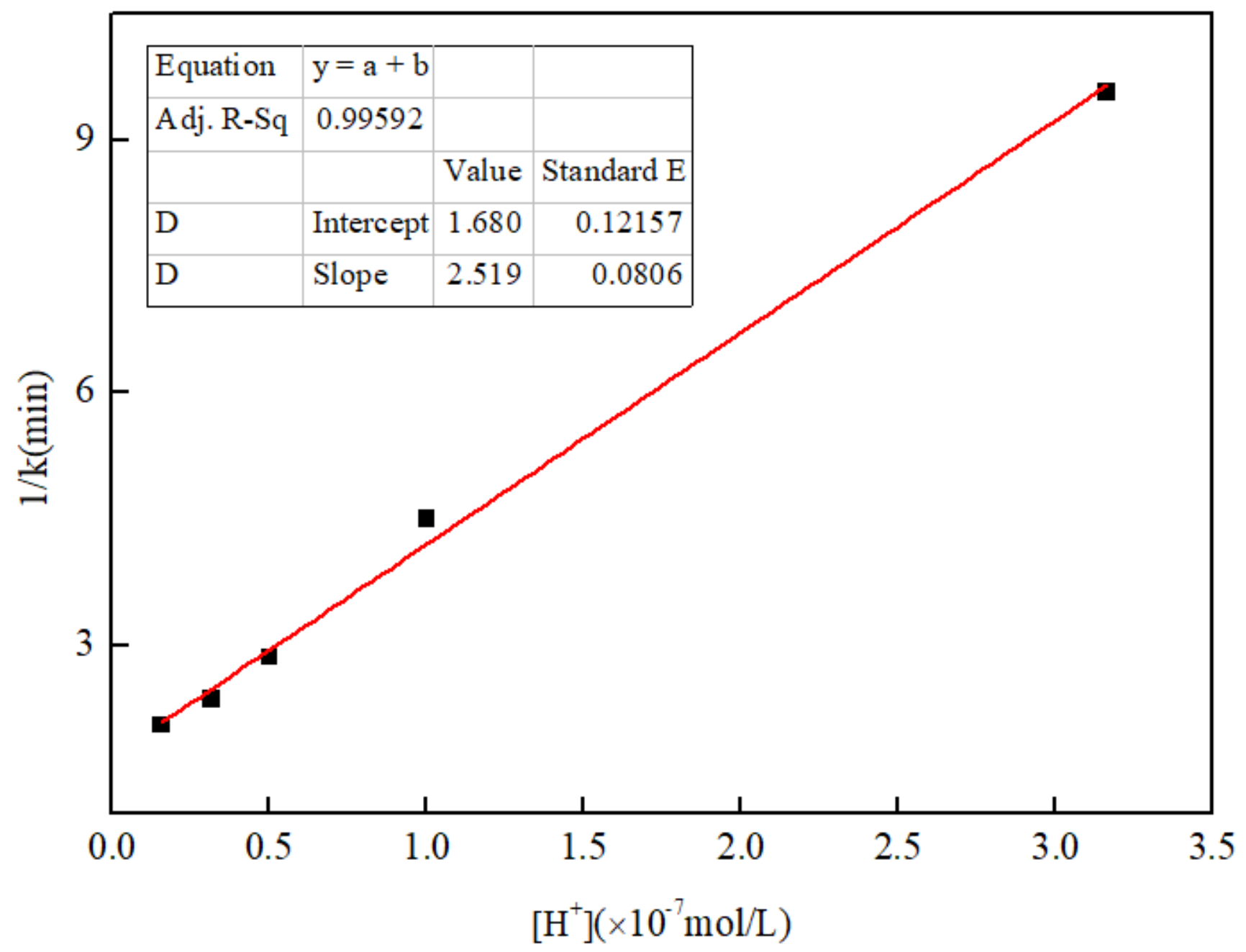

Figure 10

The relationship between $1 / \mathrm{k}$ and $[\mathrm{H}+], 298 \mathrm{~K}$, Ccat $=0.5 \mathrm{~g} / \mathrm{L}$ 


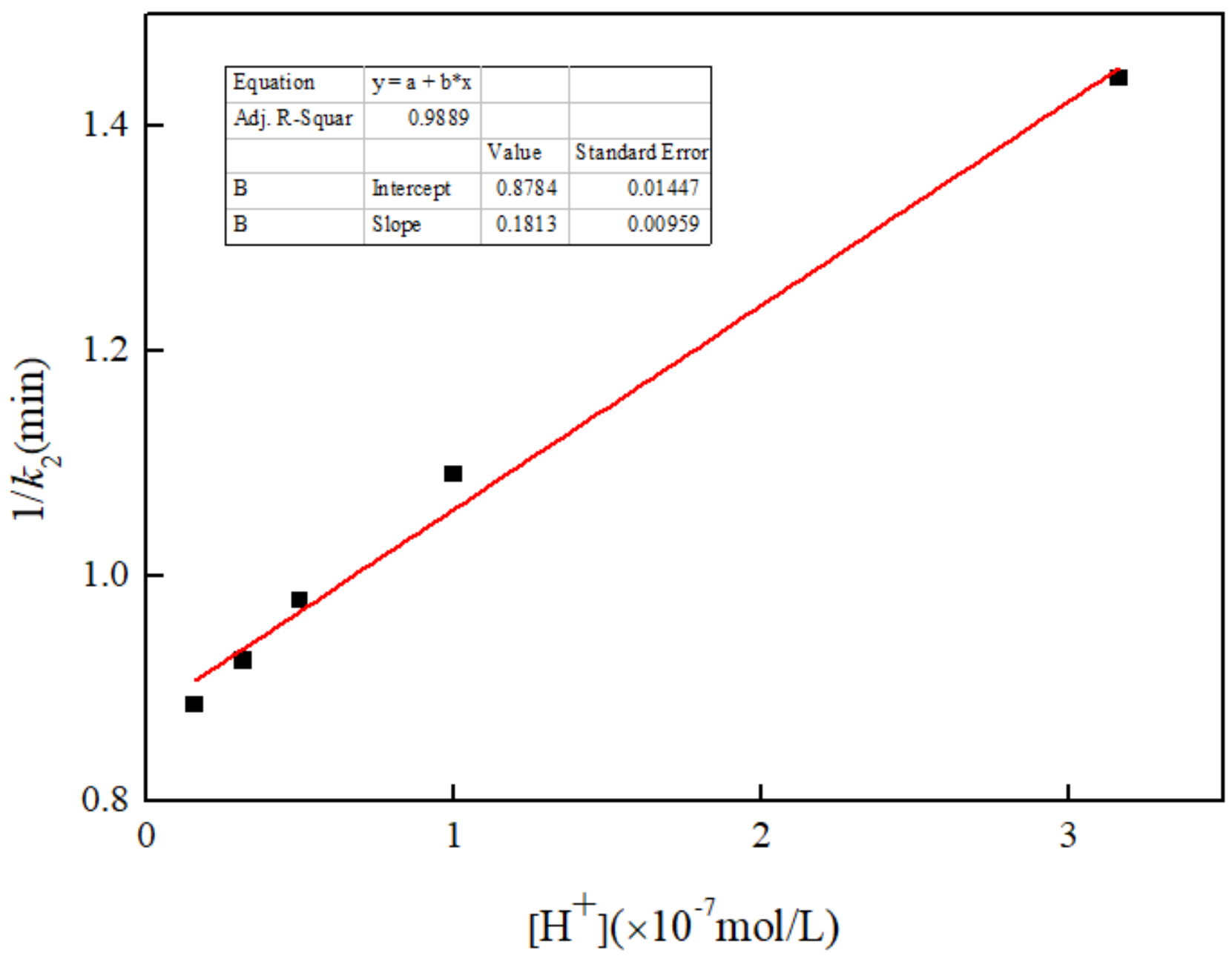

Figure 11

The relationship between $1 / \mathrm{k} 2$ and $[\mathrm{H}+], 298 \mathrm{~K}$, Ccat $=0.5 \mathrm{~g} / \mathrm{L}$ 


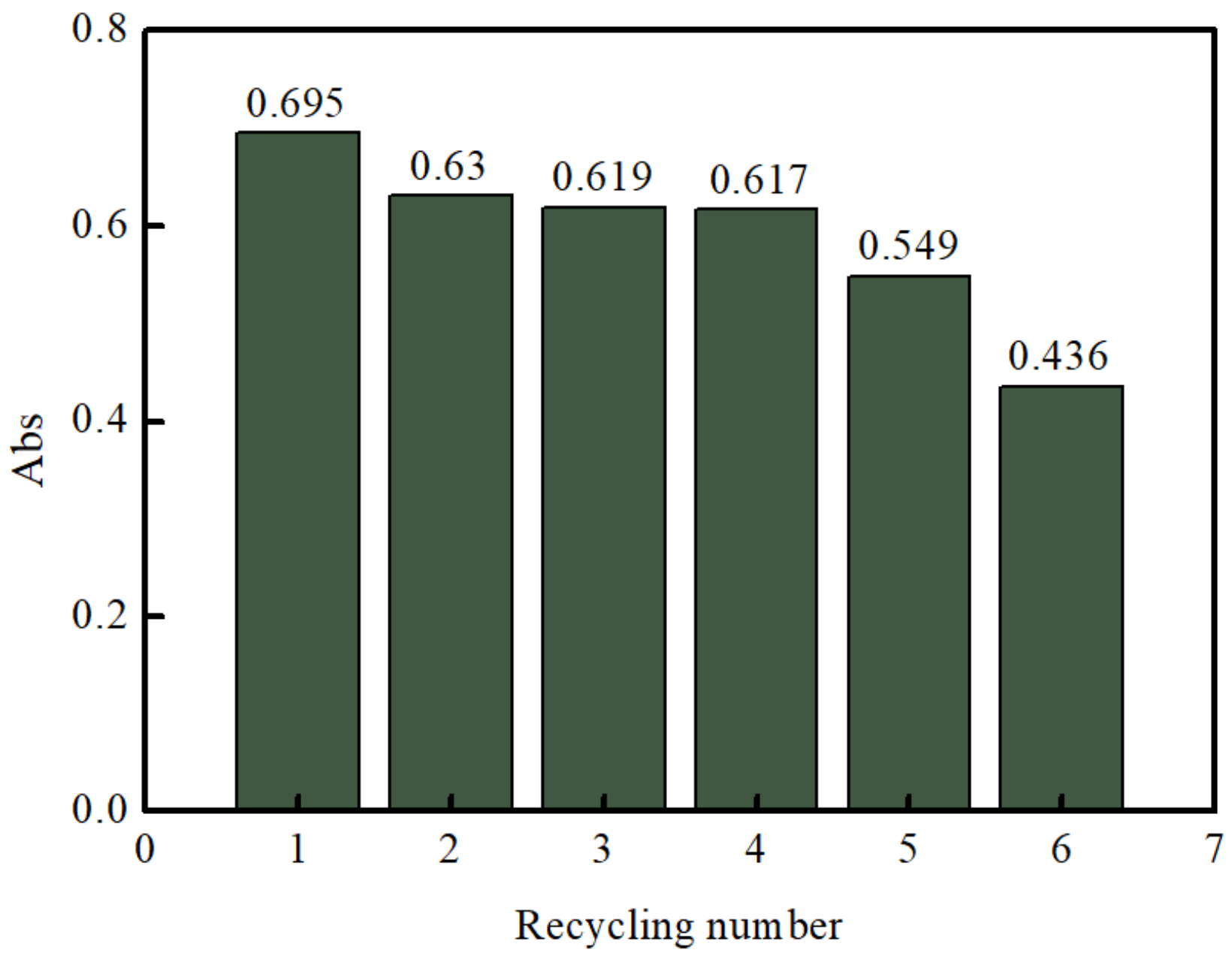

Figure 12

The stability test of PNPP catalytic hydrolysis efficiency by LaNiO3.

\section{Supplementary Files}

This is a list of supplementary files associated with this preprint. Click to download.

- GraphicalAbstract.doc 